\title{
The use of an academic library's discovery layer: an ethnographic approach
}

\author{
Elizabeth Atkinson
}

\section{September 2013}

Word count: 14,776

\begin{abstract}
Supervised by Anne Welsh
Submitted in partial fulfilment of the requirements of the degree of MA in Library and Information Studies, Department of Information Studies, University College London.
\end{abstract}

\section{Declaration}

I have read and understood the College and Departmental statements and guidelines concerning plagiarism. I declare that this submission is entirely my own original work. Wherever published, unpublished, printed, electronic or other information sources have been used as a contribution or component of this work, these are explicitly, clearly and individually acknowledged by appropriate use of quotation marks, citations, references and statements in the text. 


\section{Acknowledgements}

I would like to thank Andrew Preater for giving permission for this research to be carried out at Senate House Library and providing support during the preparation and implementation of this research; Victoria Wilson for giving permission for me to access her dissertation, which she is currently preparing for publication in article form, and to build upon it; and my supervisor Anne Welsh for her advice and encouragement throughout this dissertation. 


\begin{abstract}
For several years commentators have asserted that libraries' traditional OPACs (Online Public Access Catalogues) are failing to meet user expectations. In recent years many academic libraries have implemented discovery layers, systems designed to address the issues of traditional OPACs by allowing e-resources which are not in the library's catalogue to be searched alongside records in the library's catalogue and offering a range of features, such as a simple 'Google-like' search box, faceted browsing, a "Did you mean...?" feature, suggested alternative searches, user contributions and a more visually appealing interface. Research into how users are using discovery layers for their own research needs is limited. This dissertation investigates how users at Senate House Library are using the discovery layer Encore and which features they find useful. An ethnographic method including observation and interviews is employed to provide an in-depth insight into users' search experiences.
\end{abstract}

The main findings are that users almost universally start a search using a basic search box, rather than immediately going to advanced search. In contrast to some previous research, several users employed a thorough search approach, carefully evaluating results and looking through multiple pages of results. The idea of location is important to users at Senate House Library. The physical location of search results is not always clear to users who sometimes find a resource in Encore they wish to access only to discover the location it is in is not one to which they have access or is not one to which they wish to travel. Facets are generally found to be useful, but may not be noticed or understood. Content information such as summaries and tables of content are very important to some users. Other features were rarely mentioned or used. Recommendations for further research into the use of Encore at Senate House Library are provided. 


\section{Contents}

Acknowledgements

Abstract ii

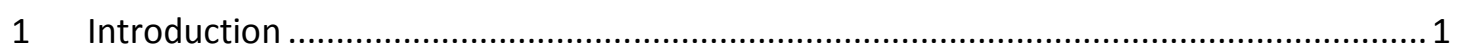

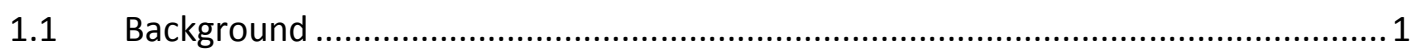

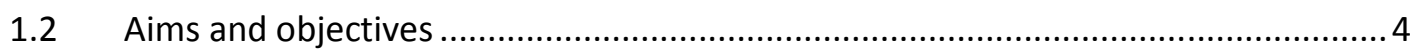

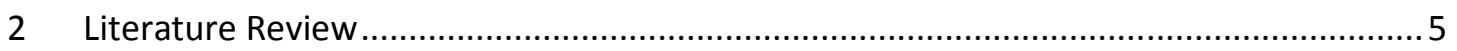

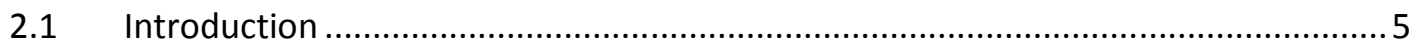

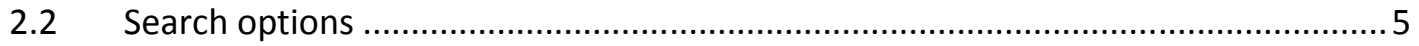

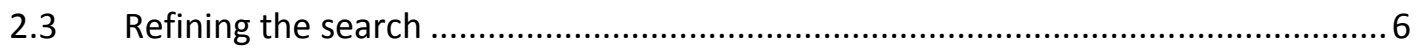

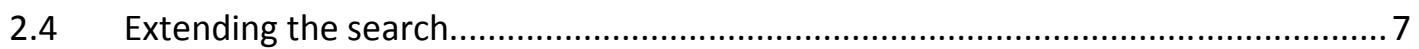

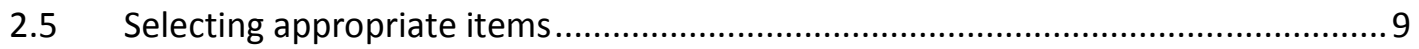

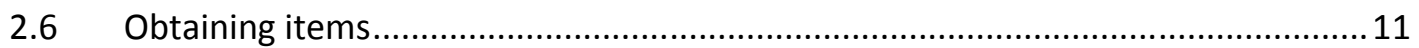

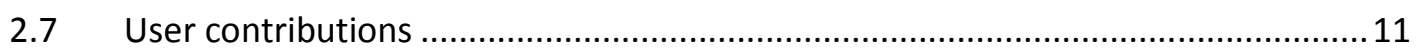

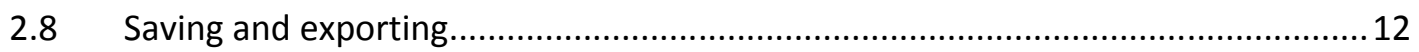

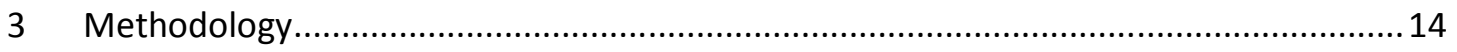

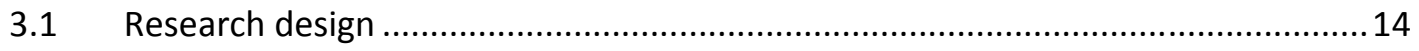

3.2 Familiarisation of researcher with the field setting ................................................15

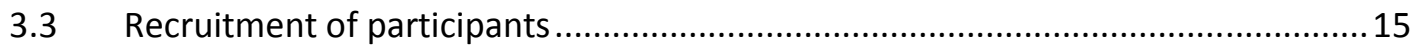

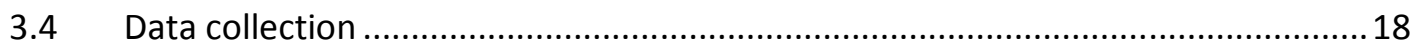

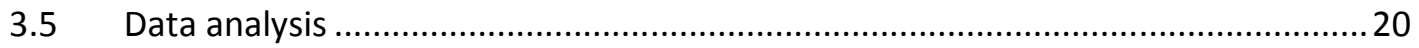

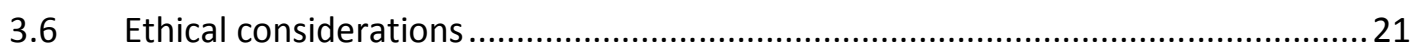

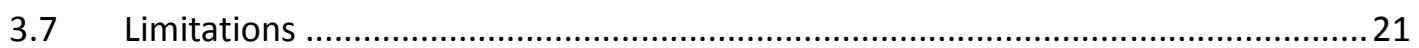

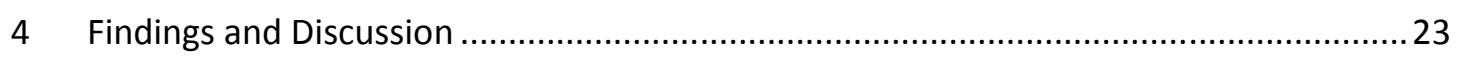

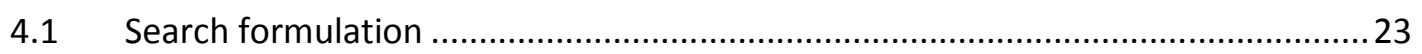

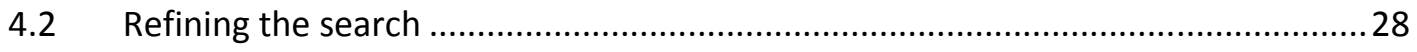

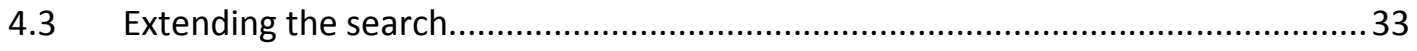

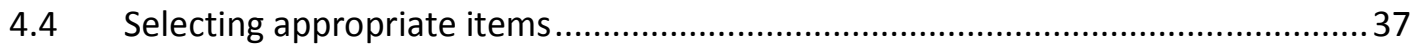

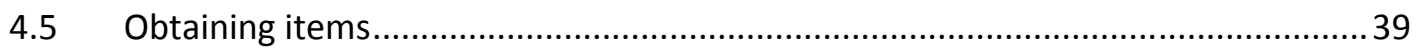

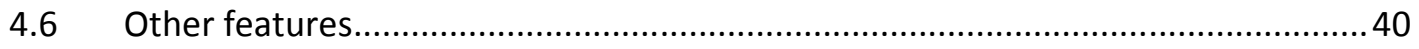

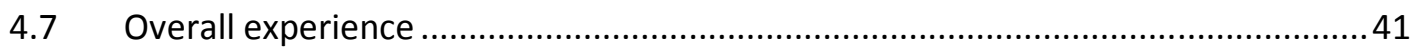

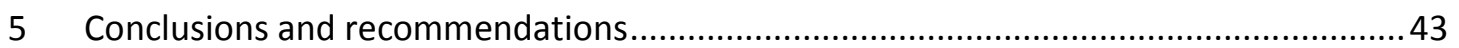

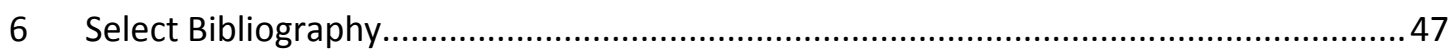




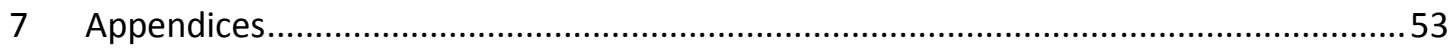

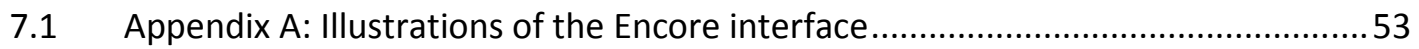

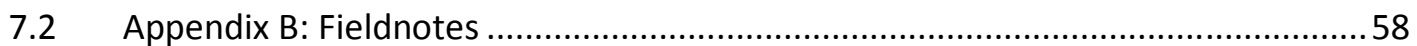

7.3 Appendix C: Demographic questionnaire results ................................................113

7.4 Appendix D: Historic collections survey results ....................................................114

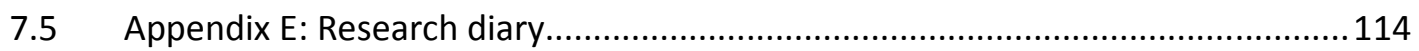

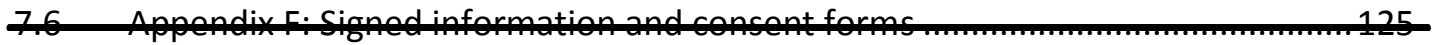

Appendix F not included 


\section{Introduction}

\subsection{Background}

By the mid-2000s libraries had started implementing a new type of OPAC (Online Public Access Catalogue), with a range of features designed to improve the search experience for the user. These OPACs were often referred to as next-generation catalogues. In his 2007 Library Technology Report Marshall Breeding outlined the features which, in his opinion, were expected of next-generation catalogues (Breeding 2007b). These features were:

- A state-of-the-art web interface in terms of appearance and navigation

- Enriched content, including cover art images, tables of content, summaries and expert reviews

- Faceted navigation

- Keyword searching

- Relevancy ranking

- A "Did you mean...?" feature offering alternative spellings

- Recommendations for other content

- User contributions

- RSS feeds for new items and relevant items in other environments, such as a class page in a virtual learning environment

Another problem with traditional OPACs was that they only provided access to items in libraries' catalogues, and not to journal articles and other resources provided by libraries' subscriptions to electronic resources. An initial attempt to address this problem was the implementation of federated search which allows a user to search multiple databases via a single interface. However, there were a number of problems with federated search, such as slow response times, problems with ordering of results and not providing access to article 
level content in the same interface as catalogue resources (Breeding 2007b). Recently there has been a focus on providing access to all content provided by the library, including electronic article level content.

To reflect the move away from including just records in the library catalogue to including items the library provides access to from other sources there has been a general, though not universal, move away from the term next-generation catalogue. This type of software has variously been termed a discovery engine, discovery layer, discovery platform, discovery service, discovery system and discovery tool, sometimes prefaced by the term web-scale to indicate the extent of the material indexed. In this dissertation the term discovery layer will be used throughout. In 2010 Breeding proposed that in addition to web-scale discovery and his previously recommended features, discovery layers should also be aiming for full-text indexing, a self-explanatory interface, a mobile friendly interface and access to all library content, including all information provided on the web about the library's services. Yang and Wagner (2010) also included integration with social network sites and persistent links in their checklist of discovery layer features for evaluating the features offered by different discovery layers.

Discovery layers are now "in a phase of routine deployments" Breeding (2012, p. 31). However, there is not universal acceptance of these systems as an improvement over the traditional OPACs they are replacing and "many would argue their proof of concept has yet to be shown" (Caudwell 2013, p. 2). Breeding $(2012$, p. 28) provides anecdotal evidence that librarians and specialised users see discovery layers as "a step backwards" and Nagy (2011, p. 26) asserts that "it is clear that these solutions have not met the demands of it [sic] users to the fullest and have not solved the problem of creating a compelling starting point for the research process." There has been an assumption that users would prefer discovery layers to mirror the design of popular web interfaces, such as Google and Amazon, which they 
encounter in their everyday lives (Sadeh 2008; Webb and Nero 2009). However, recent research has suggested that this may not be the case (Emanuel 2011; Leebaw et al. 2013). An understanding of how users actually use discovery layers is vital to justify the features present in discovery layers and to enable these systems to develop in a user-centred manner.

Although there have been numerous user studies of discovery layers, the majority are usability studies in which participants have been assigned tasks by the researchers, or transaction log analyses which provide statistical data of what users are doing but cannot gain any insight into the users' intentions or perceived level of success. Various selfreporting methods have also been used to reveal user preferences and what users say they do. It is important to note that there may be differences between the features users report they desire, the features users report they find useful and the features users actually use. In a study into preferences for discovery layer features participants rated the desirability of thirteen of the fourteen features included higher than their usefulness (Salaba and Zhang 2009). Also, it is not certain how well user behaviour when completing assigned tasks reflects what users do when completing their own tasks. Markey (2007c, p. 1128) calls for end-user searching research that is designed to "capture what end users really do, not what researchers want or expect them to do". An ethnographic approach offers the opportunity to capture users' search behaviour and experience in rich detail, revealing both what they do and their explanation for why they do it. Only one study of discovery layers which uses an ethnographic approach has been identified (Wilson 2012). This dissertation uses the ethnographic approach developed by Wilson (2012) to provide an in-depth insight into how users actually use a discovery layer in their natural search process. 


\subsection{Aims and objectives}

The aim of this dissertation is to investigate how an academic library's discovery layer is being used by the library's users, with a focus on the features offered in the discovery layer. Permission was obtained to conduct this research at Senate House Library, the central library for the University of London. Senate House Library serves a core user base of staff and students of the University of London colleges and institutes, and also offers membership to academic staff and researchers from other universities, and to private researchers. The library holds world class arts, humanities and social sciences collections.

In 2009 the library acquired Encore, a discovery layer produced by Innovative Interfaces, and launched the product as the default library catalogue in June 2011. Encore includes items available in and provided by Senate House Library, the libraries of seven institutes of the School of Advanced Study and the library of the Wallace Collection, which together comprise Senate House Libraries.

The objectives of this research are, within the context of Senate House Library, to:

1. Identify which features of Encore are used.

2. Investigate how these features are used by users during their natural use of the discovery layer.

3. Investigate which features users find useful and which they do not.

4. Produce recommendations for further research into users' discovery layer search behaviour. 


\section{Literature Review}

\subsection{Introduction}

This chapter reviews the main literature concerning features of discovery layers. A select bibliography of all material consulted in the preparation of this dissertation is provided in chapter six. The majority of the literature concerning discovery layers reports on usability testing or transaction log analysis of newly implemented discovery layers or discovery layers under consideration for implementation. Most of these studies have been conducted in academic libraries. These studies provide a valuable insight into user preferences and behaviour concerning discovery layer features. Due to the fact that discovery layers are fairly recent technology, all literature about them has been published in the past seven years. Studies of traditional OPACs, which sometimes include some discovery layer features, have also been included where they provide relevant information.

\subsection{Search options}

One of the differences between modern discovery layers and traditional OPACs is the design of the search interface with which users are initially presented. Gordon and West propose that "from a patron usability perspective simple is better" (2008, p. 54), quoting the web usability expert Jakob Nielson as saying "The best designs offer a simple search box on the home page and play down advanced search and scoping." Indeed research has suggested that users want discovery layers to be intuitive (Johnson and Craven 2010) and Holman et al. (2012, p. 260) observed that users in their study of four different discovery layers - including undergraduate students, graduate students and faculty - "almost instinctively began their first task by clicking on the search box and submitting their first query" demonstrating the pervasiveness of simple search functionality. Similar behaviour was also observed by Wilson's (2012) ethnographic study of a discovery layer. 
Levels of usage of advanced search vary greatly between different studies (e.g. Ho et al. 2009; Liu 2010; Thoburn et al. 2012). The reasons for this have not been explored, but one factor which probably plays a part is that different systems have different options available as 'advanced' and 'basic' search, which are likely to have a significant effect on users' preference for them. The majority of discovery layers have a simplified 'basic' search box which is initially presented to the user, but this can range from just simple search box plus search icon or labelled search button, to a search box plus several drop-down menus, radio buttons or check boxes to limit what is searched and how the search terms are interpreted. Usability testing of the discovery layer EBSCO Discovery Service at James Madison University, Virginia found that users desire a single search box, but find pre-search limits useful (Fagan et al. 2012). A comparative study of two academic library OPACs conducted in 2008 , one of which had the default search option of "Keyword - all fields" and the other "Title (alphabetical)", found that users tended to use the default option in both cases (Liu 2010). A number of other studies have also found that users predominantly use the default search interface (e.g. Foster and MacDonald 2013; Holman et al. 2012; Williams and Foster 2011). This suggests that either users do not carefully consider what search options they use or they assume the default will give them the best results.

\subsection{Refining the search}

Another highly proclaimed feature of discovery layers is the facets that offer users the ability to refine their search results by a wide range of options, such as format, date of publication, language and subject. They are considered a key feature of discovery layers (Breeding 2007b; 2010; Yang and Wagner 2010) and Ho et al. (2009, p. 84) proclaim facets to be the "most compelling feature for users" of the discovery layer VuFind. The importance of facets lies in their ability to allow users to easily refine their search, thus providing more relevant results. Olson (2007) asked graduate students at the University of Chicago who were 
working on their dissertation and had already used the traditional OPAC to search for relevant information to use a faceted OPAC to search for information relevant to their dissertation. Nine out of the twelve participants in this study found material they had not previously found with the traditional OPAC. Ballard and Blaine (2011) report that the use of facets in the Encore discovery layer at the New York Law School increased the proportion of searches which were refined 15 to 20 times compared to their previous OPAC.

Fagan (2010) reviews the results of user studies of library OPACs and discovery layers that incorporate faceted browsing and found that the level of usage of facets and preference for those facets varied between studies, suggesting that implementation details have a significant impact. The majority of studies suggest users appreciate facets (e.g. Emanuel 2011; Fagan et al. 2012; Foster and MacDonald 2013), but level of usage varies and both Comeaux (2012) and Bauer and Peterson-Hart (2012) found that users were confused by facets. Interestingly, Caudwell $(2013$, p. 11) reports that in a trial of the discovery layer Summon at the University of Cambridge users "routinely ignored or failed to notice the facets entirely. Instead, preferring to go to the advanced search option, they failed to find resources that could have been more easily discovered with faceting." The results of a number of other studies have also suggested that users may not notice facets (Ford 2010; Holman et al. 2012; O'Hara et al. 2012).

\subsection{Extending the search}

\subsubsection{Did you mean...?}

As mentioned above, a "Did you mean...?" feature is included as one of Breeding's (2007b) key features of a discovery layer. Between 2000 and 2003 Yu and Young conducted an analysis of transaction logs at the California State University, Los Angeles and found that almost half of failed keyword searches on their OPAC were due to misspellings or typographical errors (2004, p. 172). This suggests that a "Did you mean...?" feature which 
can suggest alternative spellings would be valuable to discovery layer users. Allison (2010, p. 377) suggests that "since researchers may lack the vocabulary used in metadata schemes developed by experts, adding functionality ... providing automated search help, such as related queries or spell checking, would benefit novice searchers." Little research has reported on use of or user opinions of "Did you mean...?" features in OPACs or discovery layers. However, in a case study of University of Sheffield international students Tam et al. (2009, p. 361) found that the majority of students interviewed (13 out of 16) thought a spell checker was "a good feature" in their university's OPAC, but only two thought it was necessary.

\subsubsection{Recommendations, related searches and subject heading links}

A range of features are offered by discovery layers to provide additional support to users who are searching by subject to enable them to expand their search. Recommendations or related material is proposed by Breeding (2007b) to be a key feature of discovery layers, but there is limited coverage of these features in user studies of discovery layers. In Novotny's usability testing study at Pennsylvania State University Libraries several participants commented "that a "Find related" or "Find more like this" button would be helpful" (2004, p. 533). This is a similar type of feature to related searches and subject heading links, providing additional support for users who are subject searching to expand their search. Antelman et al. (2006) were surprised by the high level of usage received by the "more titles like this" feature of the newly implemented Endeca discovery layer at the North Carolina State University. A related searches feature provides a list of related searches which a user can choose to click on to take them to that search. As noted above, Allison (2010, p. 377) suggests that a related searches feature would be of particular value to novice searchers.

Similar to related searches, another feature of discovery layers is the ability to initiate a search for all items with a particular subject heading by clicking on that subject heading from 
within an item record. Since users have a limited knowledge of subject headings, this can be a good way to utilize the subject headings provided by the catalogue in a way that is easy and intuitive to use. Bauer and Peterson-Hart (2012) found that subject heading links in records were used far more than subject headings in facets and in Wilson's (2012) study at a specialist institutional library survey respondents reported using subject headings to browse the catalogue. However, Whitehead (2009) reports that a focus group study at Queen's University, Ontario found that undergraduate students find subject heading links in records confusing and avoid them.

\subsection{Selecting appropriate items}

\subsubsection{Approach to searching}

Novotny (2004) reports on usability testing conducted on the Pennsylvania State University Libraries OPAC in 2002 using nine novice searchers (new first-year undergraduate students who had never used the OPAC before) and nine experienced searchers (students and faculty with experience of using the OPAC). It was found that while the experienced searchers spent time carefully reviewing search results, the novice searchers quickly scrolled through results and clicked on the first thing that seemed relevant. One participant expressed this behaviour as "I don't think I click" (p. 530). In a follow-up study looking at whether library instruction affects first-year students' behaviour when using the OPAC, this kind of behaviour was still common and the students rarely looked beyond the first page of results (Novotny and Cahoy 2006). Emanuel (2009) found that although undergraduate students were more tolerant of the limitations of a next-generation catalogue than more experienced searchers, they spent less time on their searches and were quick to abandon a search. Undergraduates rarely used more than one facet or looked at more than one page of results. If they did not immediately find what they were looking for they assumed the library did not have it. More recently usability testing with undergraduates across five different discovery 
layers also found that participants rarely looked beyond the first page of results, but in contrast to those observed in Novotny's (2004) study they tended to scan the whole page before selecting any resources to look at more closely (Majors 2012).

\subsubsection{Contents information}

Novotny's (2004) usability testing also found that summaries and chapter headings were used to assess the relevance of titles and were highly valued by participants. That users rely on summaries and tables and that they expect to find them in library catalogues were also key findings of Calhoun et al.'s OCLC report (2009). Johnson and Craven (2010, p. 240) report that participants in a usability test of Copac "particularly liked" summaries and that they would also appreciate links to Amazon reviews to provide further information on the content. Tosaka and Weng (2011) conducted a study in 2009 looking at how the presence of certain MARC tags which contain content information affected circulation at the College of New Jersey Library. Taking into account date of publication, they found that the presence of tables of content increased circulation, while summaries did not. However, there is no reason to assume circulation correlates with usefulness in the catalogue. The information in a summary or table of contents may convince someone to go and take the book off the shelf, but equally it may persuade them that it is not the right book for their need. This can still be useful as it may reduce the number of items a user needs to physically find and assess before choosing which books to take out, or it may save them a wasted trip to the library. In a study into the value of notes fields to academic library users Johnson (2012) found that over $90 \%$ of survey respondents reported they would find it useful to have contents information in catalogue records, with around half finding it invaluable.

\subsubsection{Cover art}

The inclusion of cover art (usually images of book covers) is considered a key feature of discovery layers (Breeding 2010; Yang and Wagner 2010), but there has been little research 
into users' opinions of cover art or whether they find it useful. Mi and Weng (2008, p. 10) propose that "a book cover image conveys an impression of a book that words cannot" and can be used to recognise a previously seen book. Calhoun et al. (2009) report in an OCLC report on OPAC preferences that cover art was one of the elements frequently mentioned by focus groups as most useful in finding required items. Contrastingly, in a study of the preferences of international students at the University of Sheffield, although all 16 participants made positive comments about cover art, 13 out of the 16 stated they would not find cover art useful (Tam et al. 2009, pp. 364-365).

\subsection{Obtaining items}

One of the key findings of Calhoun et al.'s OCLC report was that "the end user's experience of the delivery of wanted items is as important, if not more important, than his or her discovery experience" (2009, p. v). Allison (2010, p. 387) reported that the availability facet, which narrows the search to only items that are not on loan, is very popular with undergraduates at the University of Nebraska-Lincoln.

\subsection{User contributions}

Breeding (2007b; 2010) argues that discovery layers should encourage user contributions, such as ratings, reviews and tags. While he acknowledges that users may not be interested in such a level of involvement with library discovery layers, he notes that such user contribution is growing in a number of areas. Ho et al. (2009) report that the availability of user participation features was a key factor in choosing VuFind as the discovery layer for Western Michigan University, but that in the first month after launching VuFind the tagging and comments features were "basically unused". Leebaw et al. (2013) and Alison (2010) also reported that availability of user contribution features was a requirement when choosing a discovery layer, Leebaw et al. (p. 161) stating that there was a wish to "engage our users with library materials as much as possible". However, in contrast to Ho et al.'s 
findings, Leebaw et al. found that in a series of workshops held for faculty after VuFind was launched many faculty members showed a particular interest in VuFind's tagging feature, and Allison found that Encore's tagging feature was used by students and staff at the University of Nebraska-Lincoln. Allison found that tags were popular with librarians to add information such as journal abbreviations and book awards to records and that some faculty members were using tags to collate resources for their classes. Students were also using the tagging feature, with $28 \%$ of tags added by students (Allison 2010, p. 385 ). This leads to the suggestion that exposing students to tags may persuade them to add their own. Erb (2012) also found that the tagging feature of an academic library's discovery layer was being used, with over 18,000 user tags added in under a year, $76 \%$ of which were created by students. However, usability testing of Copac found that users were concerned about the quality of tags and felt that information in Copac should come from a trusted source (Johnson and Craven 2010). In a review of tagging in libraries Gerolimos (2013) points out that the literature is lacking in evidence for the extent of user participation in tagging in libraries and argues that the key to making tags work for libraries is "user willingness, which translates to the will of the few to devote some of their time to the online activities that a library offers" (p. 51).

\subsection{Saving and exporting}

A further set of discovery layer features influenced by Web 2.0 trends focus on making it easy for users to return to information in the discovery layer for future reference or share items they have found with others. These features include a saved list of items and searches in the user's account, exporting of items to bibliographic reference managers such as EndNote and RefWorks, and sharing via email or social media tools. These features have received relatively little attention in studies of discovery layers. Both Majors (2012) and Johnson and Craven (2010) report that users would like to be able to save items in their 
account and export references to reference management software. Although all five discovery layers included in Majors' usability testing had these features, users struggled with finding and using them. In usability testing of the discovery layer Summon at the University of Huddersfield only one out of 33 participants used the add to saved items feature, while only two used the referencing tool (Philip 2010). However, no studies have indicated whether or not this low level of use is replicated in the natural use of discovery layers. 


\section{Methodology}

\subsection{Research design}

This study aimed to investigate how users are using Encore at Senate House Library. This was a pilot project intending to elicit initial suggestions of common behaviours and illuminate important areas for further research. An ethnographic approach derived from the ethnographic method for studying OPAC use developed by Wilson (2012) was employed in this study. This method involves recruiting participants who are using the OPAC, or in this case the discovery layer, during their visit to the library, observing these users as they conduct their search and then conducting a semi-structured interview with the user (Wilson 2012, p. 36). The researcher adopts an observer-as-participant role, assuming a nonparticipatory observer function during observation and only interacting with participants after completion of the search to conduct interviews.

This method differs from traditional ethnography in some important ways. Firstly, traditional ethnography requires that the researcher becomes embedded in the field for an extended period of time, usually at least a year (Pickard 2013, p. 136). However, ethnographic methods can also be employed in shorter studies where time or resources may not permit lengthy data collection, providing the researcher is familiar with the setting and the research is focused on only one aspect of research setting (LeCompte and Schensul 1999b, pp. 88-89). This method may be referred to as focused ethnography or compressed ethnography. For example, in this study how users use Encore is the focus of the study, rather than the more extensive research focus of how the library's users find information. Although still not a common method in library and information settings, there has recently been a growth in interest in using ethnographic methods and most ethnographic studies in such settings have employed a focused ethnographic approach (Goodman 2011). Secondly, the ultimate product of traditional ethnographic studies is a written ethnography, which is a 
narrative account of the experiences of the participants. This was not the intention of this study.

This research is attempting to find out what users actually do when they use Encore and why they do what they do. An ethnographic approach was particularly appropriate because "ethnography assumes that we must first discover what people actually do and the reasons they give for doing it" (LeCompte and Schensul 1999b, pp. 1-2). Ethnography is exceptional in its ability to provide an in-depth insight into natural user behaviour alongside user reasoning for that behaviour.

\subsection{Familiarisation of researcher with the field setting}

The first stage of the research was for the researcher to familiarise herself with both Encore and the physical setting of the study. Familiarity with Encore was necessary in order to develop an understanding of the features offered by Encore, which could then be used to develop initial questions for the interviews and as a basis for a priori codes for data analysis. Familiarity with the physical setting of the study was necessary in order to plan the logistics of the study.

\subsection{Recruitment of participants}

The initial intention was to recruit an even number of participants from three groups: those using Encore in the historic collections reading room as an integral element of their use of the historic collections; those using Encore while conducting research in the other reading rooms at Senate House Library; and those using Encore on the catalogue terminals in the catalogue hall. The reason for this was speculation based on personal experience and anecdotal evidence that the users in these three different areas may be using Encore in different ways. The catalogue hall is a room located off the main entrance hall of the library containing the circulation and enquiry desks, photocopying facilities and catalogue terminals. The catalogue terminals are desktop computers which users do not need to log 
on to, intended to be used to search Encore, but which also have general internet access and various other software programs installed on them.

The initial recruitment tools were a blog post on Senate House Library's Library News blog, a Twitter post from the Senate House Library Twitter account linking to the blog post and leaflets distributed in the historic collections reading room. Unfortunately these methods were not very successful with only two participants being recruited via Twitter and no participants directly via the blog post or via the historic collections leaflets. Further recruitment methods were enlisted to achieve the required number of participants. These were to approach users as they walked through the catalogue hall, a main route through the library, to ask if they would be using Encore during their visit to the library and if they were whether they would be willing to participate in the study. Those who agreed were asked if they were able to arrange a suitable time and place immediately and if not were given a leaflet with details of the study and asked to contact the researcher to arrange a suitable time. Although several people initially agreed and took a leaflet, no one who was approached in this way contacted the researcher to become a participant. The researcher also approached people who sat down at catalogue terminals in the catalogue hall to ask if they were going to be using Encore and if so, whether they would be willing to participate in the study. This was by far the most successful method of recruitment, contributing eight participants. Only two people who were approached in this way were unwilling to participate in the study. Another method of recruitment, which was employed from the third day of the five day data collection period, was to approach all the users in the historic collections reading room twice a day and ask whether they would be using the catalogue at any time during the rest of that week and if so whether they would be willing to participate in the study. One participant, a Senate House Library user known to the researcher, was recruited by word of mouth. 


\begin{tabular}{|l|l|}
\hline Recruitment method & No. of participants \\
\hline Twitter & 2 \\
\hline Approached as initiating search in catalogue hall & 8 \\
\hline Historic collections survey & 1 \\
\hline Word of mouth & 1 \\
\hline
\end{tabular}

Table 1: Number of participants recruited via each recruitment method

In total 12 participants were recruited. However, due to poor note taking during one observation, only 11 participants' fieldnotes were analysed. Due to the low recruitment rate of most of the recruitment methods, it was not possible to evenly recruit participants using Encore in the three areas of the library as originally intended. Of the three participants recruited in advance of their visit to the library, via Twitter and word of mouth, one used Encore in the historic collections reading room and two used Encore in the catalogue hall. Therefore, ten of the participants used Encore in the catalogue hall, two participants used Encore in the historic collections reading room and no participants used Encore in other reading rooms. Of the two participants recruited in advance who used Encore in the catalogue hall, one reported that this is where she would normally use Encore when visiting the library, but the other, Participant E, reported that he would normally use Encore in his office before visiting the library and on this occasion was visiting the library only to take part in this study. Therefore, Participant E's search may not be entirely naturalistic behaviour and must be viewed with this consideration in mind. This also highlights a potential problem with recruiting participants in advance for a study such as this, where the intention is to observe behaviour during a natural library visit.

Approaching users in the historic collections reading room to ask them to take part in the study was also used as an opportunity to conduct a rudimentary survey of historic collections catalogue use to ascertain whether any particular factors may be limiting historic collections users' participation in this study and any future similar studies. It was speculated that it may be the case that historic collections users are not using Encore to find the materials they use. The survey included the questions: 
1. Have you searched the Senate House Library catalogue this week?

2. If no, do you ever use the catalogue?

3. How did you know Senate House Library had the material you are using?

The term "catalogue", rather than discovery layer or Encore, was used because this is what Encore is labelled as on the Senate House Library website and how previous study participants had referred to Encore. Nine people were surveyed over the three days and all except one of them had used the catalogue that week, although two indicated that they had only used the catalogue outside of the library before their visit. This indicates that low usage of the catalogue is not a barrier to recruiting historic collections readers. A variety of sources, including Encore, had been used to discover historic collections material. Full results of this survey can be found in appendix D.

\subsection{Data collection}

Permission was obtained to carry out the data collection phase of this research during one week in June 2013. Participants who had arranged to participate in advance were met in the entrance hall or, if historic collections users, outside the historic collections reading room. Those met in the entrance hall were then asked to go to the area of the library where they would normally search the catalogue. The purpose of the study and an outline of the process were explained to the participants and they were asked to read and sign an information and consent form (see appendix F).

The researcher took handwritten notes while observing participants conduct their search. When participants indicated they had finished their search the interview was conducted, which was audio recorded. Notes were also taken during the interview as necessary to record non-audio information, for example when participants used Encore to illustrate a point. Interviews with participants conducting their search in the catalogue hall were conducted in the same location as their search. Interviews with participants conducting 
their search in the historic collections reading room took place in an adjoining room, so as not to disturb other readers working in the reading room. This meant that in interviews with catalogue hall participants it was possible for the participant and the researcher to use the catalogue terminal to show or demonstrate functions and features of Encore, but this was not possible with historic collections participants.

The interview was concluded with a questionnaire providing demographic information, intended to assist in the interpretation of the results. The questionnaire showed that there was a good range of ages and subject collections used among the participants. As expected, the majority of participants were current University of London students or staff and there was a good distribution across taught postgraduate students, research postgraduate students and non-students (a lecturer and a researcher). No undergraduate students were recruited, most likely because the data collection phase occurred during the last week of the summer term when most undergraduates had already completed their courses for that year. It is also worth noting that four participants currently work in library or archive services, or have done so previously, and one of these participants is also a student on the UCL Library and Information Studies MA course.

Observation fieldnotes were written up the same day the observations took place, to retain as much detail as possible. Interview recordings were listened to within 24 hours of the interview to ensure recording quality was satisfactory and so that interesting themes emerging from them could be noted (see research diary, appendix E) and used to inform future interviews. Interview fieldnotes were written up at a later date, since the recordings meant that the researcher did not have to rely on notes and memory alone, and the writing up process was very time consuming. The interview fieldnotes are not full transcriptions of the interviews. 


\subsection{Data analysis}

A process of coding was applied to analyse the data. This process involved reviewing all of the data multiple times since it is commonly accepted that this is necessary when analysing qualitative data (Gorman and Clayton 2005, p. 209). Initially all fieldnotes were read through and annotated with thoughts and possible categories for coding to allow the researcher to become familiar with the data. Secondly, the data was coded using a priori codes derived from the features of the system and inductive codes suggested by the initial familiarisation with the fieldnotes. Thirdly, codes were reassessed and refined. Here, the idea of axial coding was borrowed from grounded theory, creating links between codes and clustering codes into categories (Bazeley 2012, pp. 236-237). Information from the demographic questionnaires was used during this process. The raw field notes were then assessed again against these final codes to ensure all relevant passages had been coded. The creation of a codebook and coding was carried out using LibreOffice Base, a database management program similar to Microsoft Access, using a method adapted from Hahn (2008).

Grounded theory, a method for deriving theory from data, was considered for this research, but was dismissed on two accounts. Firstly, it requires an iterative approach to data collection and analysis, analysing collected data and using results of that analysis to inform further data collection. For practical reasons data collection in this study needed to take place over a compacted period of time so all analysis was conducted after data collection. Secondly, grounded theory relies upon verification via multiple instances of a behaviour. With behaviours expected to be far from universal, particularly considering that some participants were conducting known-item searches while others were conducting subject searches, there were not enough participants in this study for this to be done. 


\subsection{Ethical considerations}

Participation in this study was voluntary and participants were free to withdraw at any time. All participants signed a consent form giving permission for the data collected to be used in this study (see appendix F). The names of participants were only collected where it was a necessary part of the recruitment process, i.e. when emailing to arrange participation in advance of their visit to the library. Participants were anonymised by storing names separately to fieldnotes and at no point associating names with corresponding field notes or audio recordings. Audio recordings of interviews were securely stored on password protected devices.

\subsection{Limitations}

There are a number of limitations inherent in the ethnographic method employed in this study. Ethnography has been criticised for a lack of validity and reliability (Schensul et al. 1999). Validity concerns the extent to which the results can be generalised to the entire population. However, ethnography is not intended to produce results which can be generalised. As pointed out by Pickard (2013, p. 21), this is a problem common to most qualitative studies and instead the principle of transferability should be applied as an evaluative criteria. Transferability relies on enough detail being provided for other researchers to determine whether the results of a study are transferable to another situation. In this study the provision of general information regarding Senate House Library and the information reported from the demographic questionnaires (appendix $\mathrm{C}$ ) addresses the criteria for transferability. Reliability is the extent to which the same results would be produced if the research were repeated using identical methods. The focus of ethnography of individual situations and experiences means that ethnographic research cannot be reliable in this sense. However, reliability is not an aim of ethnographic research. 
There are also limitations arising from the data collection methods of observation and interviewing, known as observer effect and interviewer effect. It is known that people behave differently when they are aware they are being observed (Gorman and Clayton 2005, p. 105). Covert observation was not possible both for ethical reasons and because interviews were being employed alongside observation. However, steps were taken to minimise observer effect, including asking participants to ignore the researcher while they were using Encore, the researcher sitting behind and out of sight of the participants and the researcher attempting to keep noise, such as turning notebook pages, to a minimum. Although taking notes was likely to have made participants more aware they were being observed, it was necessary in order to capture the in-depth level of detail required. During interviews the interviewer can have an effect on the responses of participants in a number of ways, including: asking leading questions, indicating a "right answer" by expressing an opinion or through non-verbal cues, and interrupting the interviewee or failing to probe topics the interviewee introduces (Schensul et al. 1999, p. 144). These behaviours were avoided during interviews to minimise interviewer effect.

There were also some limitations arising from the range of participants recruited. Undergraduate students constitute a significant proportion of the Senate House Library usership, but no undergraduate students were recruited, probably due to the timing of the study. Further research is required to determine whether the results of this study are applicable to these users. The majority of the participants recruited in this study were using Encore on catalogue terminals in the catalogue hall. It is speculated that use of Encore on catalogue terminals may differ to use of Encore in library reading rooms and outside the library. For example, use of Encore in reading rooms may be more integrated into the research process and the lack of immediate access to physical items may affect user behaviour and preferences outside of the library. 


\section{Findings and Discussion}

Observations of eleven participants' searches, which ranged from 1 to 15 minutes, and follow-up interviews produced fieldnotes which were analysed using the method described in chapter three. Screenshots illustrating the terminology used in this chapter can be found in appendix $\mathrm{A}$.

\subsection{Search formulation}

\subsubsection{Search type}

Five participants were observed conducting known-item searches and seven participants were observed conducting subject searches. These numbers include one participant who conducted both known-item and subject searches. This proportion of known-item searches compared with subject searches is in agreement with Tosaka and Weng's (2011) findings that approximately half of searches on an academic library's OPAC are known-item searches. It is relevant to ascertain the level of known-item versus subject searching since the two types of searching are expected to invoke different search methodologies and, therefore, to utilise search system features in different ways.

Two participants, both of whom are historic collections readers, reported that they only ever use Encore for known-item searching. All other participants reported that they use Encore for both known-item and subject searching, although two participants use Encore mainly for known-item searching and two participants use Encore mainly for subject searching. Participant E reports that he avoids using Encore for subject searching and will instead use other library catalogues or the Bibliography of British and Irish History to find items and then use Encore to see if they are held by Senate House Library. He finds Encore "quite good for a quick Google-type search, but not much else." In one of her observed searches Participant $\mathrm{H}$, a university lecturer, was not just using Encore to find what material Senate House Library held on her topic of interest, but "scoping out a field of what people are saying about it. Is 
there a lot of books out there? I don't actually know if it's a field." This is interesting since previous research has suggested that students and young university researchers tend to start their search for information on a new topic outside library discovery layers (Griffiths and Brophy 2005; Haglund and Olsson 2008). Whether Participant H's use of Encore in this case is typical of either her information seeking habits, or those of university lecturers more generally, remains to be seen. It should be noted that Participant $\mathrm{H}$ did not perceive this search as successful and expects that to succeed in this search she will probably have to use Google.

\subsubsection{Search interface}

When starting their search at the catalogue terminals in the catalogue hall, participants were initially presented with the quick search screen, unless a previous users' search was still displaying. Entering search terms in the quick search box without changing the drop-down options from the default conducts a search in Encore as if the terms had been entered in the search box on the main search screen or in the main search box. All participants except Participant $L$ started their search by entering terms in either the main search box or the quick search box with the default search limits. Participant $L$ uses the quick search box, but changes the drop-down option from "Quick search" to "Title" which runs a title search in the classic catalogue. These findings agree with those of Holman et al. (2012) and Wilson (2012) that regardless of experience level users, if presented with a single search box, almost universally start searching using a simple keyword search in that search box.

Seven participants were observed to use only quick search with default limits and the main search box, while three also use advanced search at some point during their search session. Of those not observed to use advanced search two report that they do sometimes use this feature. Four of the five participants who use advanced search work in a library or archives service, or have done so previously. Therefore, it may be that advanced search use among 
the whole Senate House Library usership is lower than suggested by the proportion of participants in this study who use it. Previous studies of academic library discovery layers and OPACs have reported varying levels of use of advanced search ranging from $3 \%$ of all searches (Ho et al. 2009, p. 90) to $44 \%$ of participants using advanced search at least once in a usability test of a discovery layer (O'Hara et al. 2012). Foster and MacDonald's (2013) usability testing of a discovery layer found that most of the participants used advanced search. However, the advanced search screen was the screen they were initially presented with and none of the participants had used the system before. Other studies have indicated that participants tend to use the default search interface (Holman et al. 2012; Liu 2010; Williams and Foster 2011; Wilson 2012). The wide range in levels of advanced search usage may be attributable to the varying options different institutions provide in both basic and advanced search, how these options are visually presented to the user, what the default search options are and the impact of library instruction sessions.

Three participants reported that they use advanced search because of the options it offers to refine their search, for example limiting to only books, while two reported that they use advanced search when they want to use Boolean operators. One of the participants who uses advanced search in order to use Boolean operators is a retired librarian and the other has previously worked as an archives assistant. Participant F would like the option to search by publisher added to the advanced search options, since it is important for her area of studies, book studies. Since Senate House Library holds a strong collection in this subject, this is a reasonable request.

Participants B and C, both taught postgraduate students, reported having attempted to use advanced search but abandoning it because they had problems using it. Participant B reported not being able to refine his search in the way he wanted, while Participant $\mathrm{C}$ was not able to find items she knew Senate House Library had and attributed her difficulties to 
her lack of knowledge of how to use advanced search. Without having observed these difficulties it is not possible to determine the exact problems encountered, however they suggest some users would benefit from point-of-need help in using the advanced search feature.

Two participants, $\mathrm{F}$ and $\mathrm{L}$, are observed to use the classic catalogue and a third, Participant $\mathrm{E}$, reports using the classic catalogue. Participant $L$ used the classic catalogue exclusively, but this was because he wanted to search by title and by changing the search option to title on the quick search screen, which was the screen he was initially presented with on the catalogue terminal, he was directed to the classic catalogue. When he was shown the advanced search screen in the interview he recognised it and was very positive about it. Participants $\mathrm{E}$ and $\mathrm{F}$ both reported choosing to use the classic catalogue because they find it better for searching. Participant F finds the classic catalogue easier to use and says "I did have a lot of confidence in the old catalogue. It never failed me and perhaps that's why I go back to it." It may be relevant to note that both Participant E and Participant F are over 35. Allison (2010) reports anecdotal evidence that faculty at the University of Nebraska-Lincoln prefer the traditional OPAC to an implementation of Encore.

\subsubsection{Search terms: known-item searching}

Unsurprisingly all known-item searches used words from the title, the author's name or a combination of both. Several participants report satisfaction with the ease of known-item searching. Participant K states "I've found if you look up the editors of a book generally you can find it". Participant $\mathrm{H}$ and Participant K were both observed to use Google to find terms for known-item searches. Participant K typed the title of an article into Google; from the pdf of the article which this search retrieved he copied and pasted the names of the editors of a book from one of the references into the main search box in Encore. He reported that he does not carry copies of references around with him and instead looks up references on 
Google when he uses Encore. It is therefore important to him to have access to Google on catalogue terminals and he praised this being available at Senate House Library, while at other libraries he uses it is not.

Participant $\mathrm{H}$ used Google during both of her observed known-item searches. Her first search was for a book for which she had only an extract and the author's name. She initially searched for the author's name in Encore, but since this retrieved a large number of results and she did know the title of the book she wanted she turned to Google. She searched on Google for the author's name and the topic of the extract she has, Auschwitz. From the results of this search she looked at both the Amazon page and the Wikipedia article on the author before returning to the catalogue and using words from the title as her search terms. She appeared to be looking for more information about the author and the book during her Google search, rather than just the title she needed. In her second search she started by putting an author's name into Encore. This search retrieves no results so she searches Google for the same words. The results retrieved inform her she had got the first name of the author wrong and she searches Encore for the corrected name. Again the search retrieves no results and at this point she comes to the conclusion the library does not have any books by this author.

\subsubsection{Search terms: subject searching}

Participants used a wide variety of sources for search terms and a wide variety of strategies for choosing successive search terms when subject searching. Participant $D$ used the bibliography of a book chapter she had with her to get ideas for keywords to use; Participant G used her own knowledge of her topic to think of the broadest term she could find; Participant E searched for a specific book on his subject of interest and then used part of one of the subject headings for that book as his search terms. This reflects Wilson's (2012) 
observations that searchers derive search terms from a range of sources, including internet searches, Amazon, subject headings in records and extracts from catalogue records.

Participant $L$ reported that his search was unsuccessful and attributed this to not knowing the right terms to search for. He reported that his next course of action would be to contact a reference librarian to ask for help formulating search terms. Participant $\mathrm{H}$ also reported that her subject search was unsuccessful because she didn't know what search terms to use, but she reported that she will use Google to help her come up with more search terms. Participant $\mathrm{H}$ also tried adding a " + " between two of her search terms. She reported in the interview that this was because "I find [Encore] a bit more stubborn than my one at Central. My one at Central if you put any word in it just sort of brings up anything vaguely related to it and I don't think this one does it quite as easily." One of the findings of Markey's review of end-user searching literature was that users use syntax for Boolean searching from other systems (2007b, p. 1076).

\subsection{Refining the search}

On the results screen options to refine the search are presented down the left hand side of the screen. There are seven facets: "Availability" (at the library or online), "Search found in" (author, title or subject), "Format" (e.g. book, ebook, thesis), "Location" (the library in which an item is located), "Language", "Publish date" and "Place" (from subject headings). Each facet initially shows up to five options, and where there are more than five options there is a "more $>$ " link to view the full list of options. Next to each option the number of items associated with that option is shown. There is also a tag cloud, headed "Refine by tag". The "tags" come from subject headings and community tags. Community tags can be added to records by any registered member of Senate House Libraries. A selection of the tags which are associated with the largest number of items in the results is displayed and a "[Show more tags]" link will take users to a pop-up box of the complete tag cloud. As is the norm for 
tag clouds, the size of the text is proportional to the number of items with which that tag is associated. Once either a facet option or tag is selected, it is displayed with an " $x$ " next to it which can be clicked on to remove that limit on the search results.

Two participants were observed to use facets during their search. Previous studies of discovery layers using transaction log analyses have found the proportion of searches using facets to be $8.5 \%$ to $30 \%$ (Allison 2010; Antelman et al. 2006; Ballard and Blaine 2011; Bauer and Peterson-Hart 2012; Erb 2012; Ho et al. 2009). Therefore, the level of facet usage observed is not surprising. Some usability testing studies have found far higher levels of usage (Foster and MacDonald 2013; Leebaw et al. 2013; Williams and Foster 2011), but these studies were specifically designed to test features of the system including facets and are therefore not a good proxy for natural use of a discovery layer.

For Participant $E$ the use of facets appeared to be a fundamental part of his search strategy. Before reviewing any of the results for one of his searches, he refines by "Location", "Format", "Language" and "Place". He reported finding the number of results in each category useful. This participant, who is a historian, would like more facets to be included, in particular the date range covered by the subject of the book. Since the chronological subdivision of subject headings are not included as tags, there is currently no way to refine results by the subject time period. This is something which it would perhaps be relatively simple to add to the tags or create a facet for. However, tag clouds for many searches are already large and adding to them may make them harder to use while the list of facets is already fairly long and the longer the list of facets the more likely users will miss the tags and related searches which are located below the facets. It would therefore be important to assess the desire for and potential usefulness of subject time period as a facet or as an addition to the tags before implementing it. This participant would also like to be able to 
select books that are available for loan, rather than reference books, although is not sure whether this is one of the options currently available - it is not.

Three more participants report using facets, although they are not observed doing so. No participant used or reported using the "Search found in" facet, while use and observed use of other facets showed no facet be particularly popular. Two participants used or reported to use the "Date" and "Language" facets, while all other facets were used or reported to be used by only one participant. Since several participants mentioned that they were particularly looking for books which they could borrow from the library, the lack of use of the "At the library" option in the "Availability" facet is surprising. It would be useful to investigate whether users understand the meaning of this option. Participant $\mathrm{G}$ was confused by the "Place" facet and is unsure whether it is the place of publication or the subject of the item, indicating low use of this facet could be due to uncertainty of its meaning. All previous studies reporting on the relative popularity of facets found "format" to be popular (Allison 2010; Erb 2012; Philip 2010). Other facets which were found to be popular in at least one of these studies were subject, location, availability and publication date. Olson (2007) found that users had a clear idea of which facets they would find useful, but preferred facets varied between users. Further research at Senate House Library into how popular each facet is could be valuable. This information could be used to order facets so that the most popular are at the top of the screen and most obvious to users.

Participant F reported that she uses facets and does find the "Available" facet useful for limiting to online resources, but she prefers to use the advanced search instead, saying "I suppose I'm very old school, I like to see it on the screen." It is important to consider that despite its prevalence on the web in general, and the benefits offered by facets, some users still prefer to use pre-search limits such as those provided in the advanced search interface. This supports the assertion of Breeding (2007b, p. 13) that advanced search is still important 
to some researchers and should be kept as an optional search interface in discovery layers. Participant $F$, who is a retired librarian, also expresses concern that by using the facets to refine a search she may be losing relevant results due to missing data in the catalogue. This is indeed a problem, which also affects tags, and has been noted by Caudwell (2013).

Participant B reported using an author facet when a search for an author's name retrieves results from several authors. There is no author facet in the Senate House Library discovery platform, but Participant B is a student at UCL and UCL's discovery platform does include an author facet. It is therefore inferred that it is likely that he has not clearly separated his use of the two different systems in his memory.

Two participants reported that they are aware of the facets, but do not use them because they do not need to. One of these participants, Participant A, was searching for known items and found the first item in the first page of results by using the "Find" function of Internet Explorer, while the second item was very near the top of the results list for that search. He reported only using Encore for known-item searching and not subject searching. When the correct item is easily found in the results list for a known-item search facets will not enhance a user's search experience. This participant has exploited his existing knowledge of the Internet Explorer "Find" function to quickly find a known item when it is not immediately visible in the results list.

Participant $\mathrm{K}$ reported never finding it necessary to use the facets, but since he had expressed a preference to sometimes search for items in a particular location I asked if he is aware he can use the location facet to refine by location. His response is "Ah, yeah and I have sort of noticed that at the time and then I forget how to do it so it's all very spontaneous." This reported "forgetting" suggests that either the facets themselves are not very obvious, i.e. he forgets that the option to refine by location is there and does not notice it, or that he notices them but finds them difficult to use and forgets how to use them. 
Previous studies have reported difficulties understanding facets in OPACs and discovery layers (Comeaux 2012; Emanuel 2009; Fagan 2010; Ramdeen and Hemminger 2012), though the reason for this is unclear.

Three of the participants who reported not using facets did not do so because they were unaware of them or did not understand their purpose. Two participants had never noticed the facets, while the third had noticed the facets but had always "ignored" them and was not aware she could use them to refine her results. Once the purpose of the facets had been explained, the two participants who had never noticed the facets commented that they would find them useful. This is not the first study to find that users do not always notice facets. Caudwell (2013), Ford (2010), Holman et al. (2012) and O'Hara et al. (2012) all report users not noticing facets. Caudwell $(2013$, p. 12) notes that this behaviour is surprising and suggests that "Is it that they [facets] are just not what users expect to see on a library site?". Perhaps it relates to the kind of behaviour observed by Novotny in usability testing of Pennsylvania State University Libraries' OPAC, that most novice users scroll through the results quickly and click on the first thing that seems relevant, rather than evaluating all their options; expressed by one participant as "I don't think I click" (Novotny 2004, p. 530). However, all three participants in this study who did not notice the facets were observed to slowly scroll through the results, with two of them looking at multiple pages of results. This suggests the "I don't think I click" attitude is not the root of the problem here. It is interesting to note that all previous studies detecting this issue were studies of the discovery layer Summon. In usability testing of three different discovery layers Holman et al. (2012) found that while participants using EBSCO Discovery Service immediately noticed the facets, the facets in Summon were overlooked by participants, suggesting that interface design may be behind this problem. Holman et al. (p. 258) propose the facets' "subtle integration into the layout" as the cause. 
In the case of tags, two participants were observed to use them, two participants reported that they are aware of them but do not find them useful and two participants were not aware of them but once they were pointed out thought they would be useful to them. During her search Participant D opened the "[Show more tags]" link and appeared to carefully consider all the tags before selecting one. Participant $F$, the other participant who is observed refining a search by a tag often forgets about the tags because they are "hidden down the bottom" and she would like them to be higher up the page because she finds them more useful than the facets. Tags were very rarely mentioned in the interviews. Whether this is primarily due to them not being noticed, users not wanting to refine their search in this way or users not understanding what they are is not clear.

\subsection{Extending the search}

Users are provided with several ways to extend or alter their search without entering new terms in a search box in Encore. When a keyword search returns very few or no results the reader is presented with a suggested alternative word or spelling which will yield more results. The suggested word is a hyperlink for a keyword search for that word. For example, if a search for the word "patterm" is run, the message "No catalog results found. for patterm. Did you mean: pattern?" is returned. At the bottom left of the results page, below the results list is the "Recent searches" feature. This provides a hyperlinked list of the past four searches the user has conducted in that search session, with a "+ more" link which extends the list to include all searches in the current session. On the results page on the left of the screen, below the facets and "Refine by tag" options is the "Related searches" feature providing a list of similar searches the user may want to try. Also providing access to similar material are the subject headings within full records. Clicking on a subject heading takes the user to a search for all items with that subject heading. All of these features, except linked subject headings, were observed to be used and mentioned in interviews very little, if at all. 
Only Participant D was observed to use the "Did you mean...?" feature and no other participants report using it. It may be relevant to note that Participant $D$ is a Library and Information Studies student, and therefore may be more aware of potential discovery layer features than other users. Several participants were not presented with this feature during their observed search because none of their searches returned a small enough number of results. Although no other participant used this feature it, it is not clear whether they did not do so because the alternative suggested was not what they were looking for, because they did not notice it, or for some other reason. Participant $D$ ran several searches which returned no results, therefore activating this feature, but only clicked on the link once. She mentioned later that on at least one of these occasions she had seen the link, but the suggestion was not what she was looking for.

No one was observed to use the "Recent searches" feature. Participant C noticed it during the interview and said she had never noticed it before, but thought it might be useful to her. While Participant $D$ stated in the interview that she would like it to be more obvious because she finds it useful but often forgets that it is there. This suggests that the location of this feature may be resulting in users not noticing it and therefore not having the opportunity to make use of it. Since it is currently below the bottom of the results list (see appendix A) many users may never even scroll down far enough for it to be present on their screen. At the left of the screen below the "Related searches" may be a better positioning for it.

Only one participant, again Participant $D$, is observed to use the "Related searches" feature. She scrolls past the results list to get to the "Related searches", suggesting she was specifically looking for it, rather than noticing it and spontaneously using it. Participant $\mathrm{H}$ was not aware of the feature, but when it was pointed out during the interview she says that although she does not think it would normally be helpful to her, it may have been useful for 
one of her searches as it was a topic she did not know anything about. Participant E reports that he does not find the "Related searches" feature useful.

The reason for the low level of use of these features is unclear. No interview questions were aimed specifically at obtaining information about these features. Possible reasons for their low use are that they are not noticed, users do not understand their purpose, users do not believe they will be useful, or they are only useful in a small minority of searches. It is unlikely that users do not understand the purpose of these features, particularly the "Did you mean...?" feature, which is common in web search engines and other search interfaces on the web. Since the "Did you mean...?" feature is designed for when a search fails, it is likely that this will only be of use in a relatively small proportion of searches. Several previous studies have found that users do not always notice features that will be useful to them (e.g. Caudwell 2013; Ford 2010; Holman et al. 2012). This may be because users are focusing on the results list, as was suggested to be the case by results of eye-tracking in Holman et al.'s (2012) usability testing, possibly because they are not expecting to find additional features on the results page.

Two participants, E and F, are observed to use subject heading links in full records and Participant $L$ reported that he also does this. Interestingly, this appears to be a key search strategy for these participants who all report specifically looking for items with the intention of finding relevant subject headings. Participant E clicks on a subject heading link, which retrieves a results list of eight items, at which point he declares this list of items is what he wants. At no previous point in his search had he shown any signs of noting down the details of an item or any other behaviour which suggested he had discovered an item that satisfied his search requirements. Participant $L$ reported that he uses a title search to find one relevant item on his topic, then selects a subject heading from that item to retrieve all the other items on that topic. Participant F reported a similar strategy: "I often find if I find 
something looks vaguely correct I can go in and find the Library of Congress subject heading and clicking on that, that does find me things quicker". It may be relevant to note that all of these participants are over the age of 35 , and therefore probably learnt research techniques when card catalogues were still prevalent. This could therefore be an adaptation of a search method for subject searching learnt from card catalogues. Considering the variable extent to which subject headings have been provided for records in the Senate House Library catalogue, the reliance these users place on this method of searching could be a cause for concern. Participants $\mathrm{F}$ and $\mathrm{L}$, one a retired librarian and the other previously an archives assistant, report an awareness of this lack of data and are therefore aware that such a search may not retrieve every item the library holds on that topic. Both show a sense of frustration at this limitation. However, although Participant E states that he would expect his search to retrieve more items, he shows no signs of an awareness that some records may be lacking in subject headings. This is potentially a cause for concern since users using this search strategy may assume the library is lacking in material on their topic of interest, rather than pursuing further search strategies.

Participant $\mathrm{C}$ reported that she finds subject headings very useful, but was unaware that they were hyperlinked and could be used to search for other items on the same topic. However, when I tell her this in the interview she clicks on one of the subject headings in the record that is on the screen at the time and finds an additional book she wants to look at that she had not found in her search. This suggests that linked subject headings can also be of use to younger searchers who have never known a card catalogue, but that lack of awareness or understanding of their function may be a barrier to their use. Whitehead (2009) reports that undergraduate students at Queens' University, Ontario find subject heading links confusing and avoid them, while contrastingly Bauer and Peterson-Hart (2012) found that 23.5\% of all searches in Yale University's discovery layer were the result of a user clicking a subject heading link. It would be valuable to conduct further research into 
whether users are realising that the subject headings are links, and if so where they think these links will take them. It may be the case that some short explanatory text is necessary to make their function obvious to users.

\subsection{Selecting appropriate items}

\subsubsection{Search approach}

Seven of the participants observed adopted a thorough approach to identifying items from the results list, scrolling slowly through the results list. Only one participant who was subject searching, Participant E, did not adopt this kind of approach. Four of the participants also looked at multiple pages of results. This behaviour contrasts with that observed by several previous studies (Majors 2012; Novotny 2004; Novotny and Cahoy 2006; Williams and Foster 2011) which involved changing search terms rather than looking beyond the first page of the results. However, participants in all these studies, except Williams and Foster's study which included only six participants, were all undergraduate students. Novotny (2004) and Emmanuel (2009) have both found that undergraduates behave differently to more experienced searchers, who spend more time looking for what they want and more often look at multiple results pages. In this study, the lack of undergraduates recruited may have led to an artificially high proportion of participants adopting this more thorough approach to the evaluation of search results. The difference between undergraduates and more experienced searchers could have a number of causes: experience with library search systems may lead to a belief that persistence produces worthwhile results; experienced searchers may have a different type of information need which results in a different search strategy; and it is likely that more experienced searchers first learnt to use a library OPAC before relevancy ranking was introduced to these systems and this may still affect their expectations and behaviour. 


\subsubsection{Use of short and full records}

Six participants were observed to note down the details of items from short records without going to the full record. This suggests that all the information they needed to decide that they wanted to look at these items was contained in the short record. Four of these participants were conducting known-item searches. This fairly high level of use suggests short records are serving their purpose and making it quicker for users to find items for which they do not need fuller details. Participant B reports that he only looked at the short record because he knew what he was looking for and when he is "in more of a browsing state of mind" he uses full records. Participant F reports that she finds it frustrating that she has to go to the full record to view the subject headings. However, including subject headings on short records would significantly increase their size and make the results list longer and look more cluttered.

Of the six participants observed to use short records, three also opened at least one full record. In total seven participants were observed to open at least one full record. Participant $\mathrm{H}$ goes to the full record to find the date of publication, even though it is present in the short record. She reported that it is not in the short record on her home institution's discovery layer, so she expects to have to go to the full record to find it.

\subsubsection{Summaries and tables of contents}

The presence of information about the content of an item was something about which some participants felt strongly. Participant G said during her search "One of the problems with the catalogue is that it doesn't always tell you what the book is about". Five participants reported finding tables of contents in records useful, with Participant $\mathrm{C}$ stating that they are "very, very useful" and Participant $L$ reporting that they are the most useful part of the record, particularly for edited volumes. Participant E reported that he only uses the table of contents for edited volumes, otherwise he prefers to look at the book to decide whether it 
will be useful. Two participants reported that they find summaries useful. Both of these participants find summaries more useful than tables of contents and Participant G reported that if there is no summary she will Google the book to find out what it is about. Participant C clicked on the persistent link in a full record during her observed search. When questioned about this afterwards she reported expecting it might take her to a table of contents and a few pages "like Amazon". The importance of contents information reported by these users supports previous findings that summaries and tables of contents are highly valued by users (e.g. Calhoun et al. 2009; Emanuel 2011; Johnson and Craven 2010).

\subsubsection{Subject headings}

Four participants reported finding subject headings in item records useful. It may be relevant to note that two of these participants have worked in libraries. Participant F finds it odd and frustrating when a subject heading is attached to only one book, while Participant $\mathrm{L}$ is frustrated by records without any subject headings.

\subsubsection{Book cover images}

Participants $\mathrm{C}$ and $\mathrm{E}$ reported liking the presence of book cover images in the discovery layer. Participant $\mathrm{C}$ does not know why she likes them, echoing participants interviewed by Tam et al. (2009) who all liked book cover images, but mostly did not think they were useful. Participant E reported using book cover images to recognise an edition of a book he has previously read.

\subsection{Obtaining items}

\subsubsection{Availability}

Immediate availability was obviously a priority for some of the participants. Participants C and $\mathrm{H}$ were specifically looking for books they could borrow that day, Participant $\mathrm{B}$ reported that availability status is one of the most useful pieces on information in Encore and 
Participant $\mathrm{E}$ would like to be able to refine searches to just books available for loan and not reference books. This supports Calhoun et al.'s (2009) findings that availability and accessing a resource is as important, if not more important, than discovering it. Participant I reported that there is a lack of clarity when requesting stack material regarding whether the item will be borrowable or only available for reference.

\subsubsection{Location}

Location of physical items was also an important issue for six of the eleven participants. Encore includes records for items in the eight separate libraries of Senate House Libraries. However, many users do not have access to all these libraries and even if they do, they may want to look for items from a specific library. Participants $\mathrm{F}$ and $\mathrm{H}$ reported having found an item they want on Encore and then discovering it is in a library they do not have access to. Participants $\mathrm{C}$ and $\mathrm{K}$ report that even though they have access to multiple libraries, they do not always have the time to go to another library or they may just want to search for what is available in a particular library. Participant $\mathrm{K}$ would like the option to either search all libraries or limit the location and both Participants $\mathrm{K}$ and $\mathrm{E}$ both suggested there should be a location drop down box on the main search page and next to the main search box to limit the search before retrieving the results. Since problems resulting from users finding items that were not available in the library they had intended to search in elicited such strong feelings from several users this is an important issue to address.

\subsection{Other features}

The exporting references feature of Encore was only mentioned by one participant, who had difficulties exporting references to EndNote and resorted to going to Copac to export the references instead. Only Participant D was observed to use the "Save items" feature of Encore. This feature only saves items for the duration of a user's session and both Participants $\mathrm{D}$ and $\mathrm{E}$ reported they would like to be able to save items permanently on their 
account. Participant F had not realised items were not saved permanently and thought she had not managed to get the feature to work properly, so felt frustrated with it. The low observed usage of this feature is in line with findings of previous studies (Holman et al. 2012; Philip 2010). Holman et al. (2012, p. 258) attributed this to the "subtle integration into the layout" of this feature in the Summon discovery layer. Other studies have revealed users' desire to be able to save records and also to export them to reference management software (Johnson and Craven 2010; Majors 2012).

None of the features displayed on the right hand side of the screen when viewing a full record were observed to be used or mentioned by any of the participants. This includes links to the previous result and next result in the search list; links to a search for the item or topic in the classic catalogue and "other resources", including bibliographic databases, other library catalogues and Amazon; and recently added items from the search results. Neither was the possibility for users to tag records observed or mentioned except that Participant $\mathrm{K}$ said that he does not know what a community tag is and would not use it. Whether this is because these features are not noticed, they are not understood or they are not perceived to be useful is not clear.

\subsection{Overall experience}

Feedback on the overall impression of Encore varied between participants. Participants C, K and $\mathrm{L}$ were positive about Encore. Participants $\mathrm{E}$ and $\mathrm{H}$ were less complimentary, respectively describing Encore as "middle-ing as a catalogue" and "fairly bog standard". Participant E thinks Encore is "too simple" and not good for "advanced searching". Participant $\mathrm{F}$ perceives Encore as being aimed more towards undergraduates than postgraduates, with the main search box rather than advanced search as the default search interface. She does not think Encore is very good for subject searching. 
Seven participants mentioned other library's catalogues, which may include traditional OPACs and discovery layers, in the interview. Five of these specifically compare the features of Encore at Senate House Library to those of another OPAC or discovery layer; sometimes favourably, sometimes unfavourably. It was clear from this that other library's OPACs and discovery layers are driving users' expectations of Encore. Two participants displayed expectations derived from Amazon; Participant $\mathrm{C}$ when she clicked on the persistent link in a full record and expected to be taken to something similar to Amazon's look inside feature and Participant $\mathrm{G}$ when she says that Encore does not give her enough information about the book, it doesn't provide a summary "like Amazon does". 


\section{Conclusions and recommendations}

As a pilot study this research has indicated a number of areas which merit further research at Senate House Library:

1. Are users aware of the location of items included in their search results and would users appreciate a drop-down menu on the main search screen allowing them to choose an individual location to search? Finding items and then discovering they were not in the location the participant had intended to search was a problem for several participants in this study. If it is the case that users are generally not aware of the location of items in their search results, ways of making this obvious on the results page can be investigated. Two participants suggested that adding a dropdown menu on the main search page would be useful.

2. How often do users have difficulties with advanced search and what are the sources of these difficulties? The results of this study suggested that some users do not find advanced search intuitive to use and therefore abandon attempts to use it. If the causes of these difficulties can be discovered appropriate point-of-need help can be provided to assist users in the use of this feature.

3. Are users aware of facets and tags? This study suggests that a significant proportion of users may fail to notice these features at all and therefore miss out on the benefits they offer. It is important to discover whether this is the case and how they can be made more noticeable if it is.

4. Are the purposes of facets and tags obvious to users? The lack of use of facets which would solve problems participants encountered, e.g. wanting to retrieve items from a particular location and wanting only items currently available, coupled with reported confusion regarding the "Place" facet, suggest users may not 
intuitively understand facets. If this is found to be the case point-of-need help should be offered in using these features.

5. Which facets are used most? This study indicates the majority of facets currently available are used, but did not have enough participants to give an indication of popularity. Popularity could be used to order facets so that the most popular are placed in the most visible position at the top of the page.

6. Is there low use of the features available in Encore for extending the search? If so, why is this? The results of this study indicate low usage of these features, but are not able to offer an explanation. Not noticing these features, not understanding their function or not perceiving them to be useful are all possible reasons for low usage.

7. Do users realise that the subject headings are links, and if so where they think these links will take them? One participant who stated that she finds subject headings useful had not realised they were hyperlinked, but thought this a very useful feature when it was demonstrated in the interview.

8. How useful are tables of contents and summaries to users? Several participants in this study mentioned they found these useful and some participants felt strongly about this. However, this information is only available for some records in the catalogue. If a significant proportion of users find this information useful it would be worth investigating possibilities for providing this information in more records.

9. Is there demand for a "Save items" feature that will save items permanently on a user's account? Three out of the eleven participants in this study requested this feature, since currently items are only saved for the duration of a search session.

10. Do users want to export items to reference management software, and if so what software are they using? This study indicated that this feature is currently not easy 
to use, but there is low demand for it, so it is a feature which may not need to be supported.

11. Are users noticing features presented on the right hand side of the screen? None of these features were mentioned or used in this study, but no data was collected to suggest whether this is because users are not noticing them or because they are choosing not to use them.

12. Is there any demand for community tagging? This is a feature which is offered in Encore, but which was not observed to be used or mentioned by any participants.

A range of research methods would be required to address all of these questions. Some can be answered through collection and analyses of transaction log data, some through user surveys, while others would be most suited to further ethnographic research.

Recommendations regarding recruitment of participants in similar future studies can also be formulated from the experiences during this research. In this research the only recruitment method which yielded a significant number of participants was approaching potential participants as they were about to initiate a search on Encore. However, due to the large size of the library and the fact that library users are usually doing something other than searching on Encore, it was not possible to recruit participants in the reading rooms using this method. Participant E's behaviour suggests that recruiting participants in advance of their visit to the library may mean that they visit the library only to participate in the study, negatively impacting on the how naturalistic their behaviour is. Since the aim of ethnographic research is to capture natural behaviour, it may be better to recruit participants once they are already in the library. One suggestion would be to inform users as they enter the library that the study is being conducted and ask them to contact the research team just before they initiate a search. A continuously monitored email or Twitter 
account could dispatch a researcher to participants with relative immediacy. A potential barrier to using this method would be the high level of staffing it would require.

Another problem with recruitment was persuading people who were not immediately about to start searching to participate. Some form of reward could be used as an incentive to encourage participation; a "modest payment or small gift" is not uncommon in ethnographic studies (LeCompte and Schensul 1999b, p. 196). However, whether some form of reward should be given to participants is "a subject of some debate" (Wiles 2013, p. 32). Although a reward can be seen as compensation for the time participants give up to participate in a study, there are concerns that rewards can negatively impact on the ability of participants to freely give informed consent (Wiles 2013, p. 33). This can happen if the reward is such that potential participants feel that they cannot afford to not take up the offer. Therefore, providing a small gift of little monetary value is recommended as a method for encouraging participation, while avoiding coercing potential participants into participating.

This research has provided an interesting insight into how users are actually using Encore at Senate House Library as part of their use of the library. The ethnographic method combined observation of natural search behaviours with user explanations of search behaviour to produce an understanding of the search experience from individual users' perspectives. The findings of this small study have indicated user behaviours which provide further areas for research, while the success of the study supports Wilson's (2012) conclusion that despite the additional effort, the in-depth results of ethnography make it a worthwhile method in the field of library catalogue user studies. 


\section{Select Bibliography}

Allison, D., 2010. Information portals: the next generation catalog. Journal of Web Librarianship, 4(4), pp.375-389.

Antelman, K., Lynema, E. \& Pace, A.K., 2006. Toward a twenty-first century library catalog. Information Technology and Libraries, 25(3), pp.128-138.

Asher, A. \& Miller, S., No date. So you want to do anthropology in your library? or A practical guide to ethnographic research in academic libraries, The ERIAL Project. Available at: http://www.erialproject.org/wp-content/uploads/2011/03/Toolkit3.22.11.pdf [Accessed May 13, 2013].

Ballard, T. \& Blaine, A., 2011. User search-limiting behavior in online catalogs: comparing classic catalog use to search behavior in next-generation catalogs. New Library World, 112(5/6), pp.261-273.

Baker, L., 2006. Observation: a complex research method. Library Trends, 55(1), pp.171189.

Bauer, K. \& Peterson-Hart, A., 2012. Does faceted display in a library catalog increase use of subject headings? Library Hi Tech, 30(2), pp.347-358.

Bazeley, P., 2013. Qualitative data analysis: practical strategies, Los Angeles: Sage.

Bernard, H.R. \& Ryan, G.W., 2010. Analyzing qualitative data: systematic approaches, Los Angeles: Sage.

Breeding, M., 2007a. Thinking about your next OPAC. Computers in Libraries, 27(4), pp.2830.

Breeding, M., 2007b. Next-generation library catalogs. Library Technology Reports, 43(4), pp.5-42.

Breeding, M., 2010. The state of the art in library discovery 2010. Computers in Libraries, 30(1), pp.31-34.

Breeding, M., 2012. Looking forward to the next generation of discovery services. Computers in Libraries, 32(2), pp.28-31.

Calhoun, K., Cantrell J., Gallagher, M. \& Hawk, J., 2009. Online catalogs: what users and librarians want: an OCLC report, OCLC. Available at: http://www.oclc.org/content/dam/oclc/reports/onlinecatalogs/fullreport.pdf. [Accessed May 13, 2013].

Caudwell, J., 2013. An A-Z of RDSs. The Serials Librarian, 65(1), pp.1-24.

Comeaux, D.J., 2012. Usability testing of a web-scale discovery system at an academic library. College \& Undergraduate Libraries, 19(2-4), pp.189-206.

Crabtree, A., Nichols, D.M., O'Brien, J., Rouncefield, M. \& Twidale, M.B., 2000. Ethnomethodologically informed ethnography and information system design. Journal of the American Society for Information Science and Technology, 51(7), pp.666-682.

Craven, J., Johnson, F. \& Butters, G., 2010. The usability and functionality of an online catalogue. Aslib Proceedings, 62(1), pp.70-84. 
Denton, W. \& Coysh, S.J., 2011. Usability testing of VuFind at an academic library. Library Hi Tech, 29(2), pp.301-319.

Du, J.T. \& Evans, N., 2011. Academic users' information searching on research topics: characteristics of research tasks and search strategies. Journal of Academic Librarianship, 37(4), pp.299-306.

Emanuel, J., 2009. Next generation catalogs: what do they do and why should we care? Reference \& User Services Quarterly, 49(2), pp.117-120.

Emanuel, J., 2011. Usability of the VuFind next-generation online catalog. Information Technology and Libraries, 30(1), pp.44-52.

Erb, R.A., 2012. Encore Synergy implementation at a medium-sized university library: unforeseen challenges and opportunities. In M.P. Popp \& D. Dallis, eds. Planning and implementing resource discovery tools in academic libraries. Hershey, Pennsylvania: Information Science Reference, pp. 516-534.

Fagan, J.C., 2010. Usability studies of faceted browsing: a literature review. Information Technology and Libraries, 29(2), pp.58-66.

Fagan, J.C., Mandernach, M.A., Nelson, C.S., Paulo, J.R. \& Saunders, G., 2012. Usability test results for a discovery tool in an academic library. Information Technology and Libraries, 31(1), pp.83-112.

Fidel, R., 2011. Approaches to investigating information interaction and behaviour. In I. Ruthven \& D. Kelly, eds. Interactive information seeking, behaviour and retrieval. London: Facet, pp. 61-75.

Ford, L., 2010. Better than Google Scholar? Presented at Internet Librarian 2010. Monteray, California. Available at: http://conferences.infotoday.com/documents/111/a105 ford.pdf [Accessed May 13, 2013].

Foster, A.K. \& MacDonald, J.B., 2013. A tale of two discoveries: comparing the usability of Summon and EBSCO Discovery Service. Journal of Web Librarianship, 7(1), pp.1-19.

Gerolimos, M., 2013. Tagging for libraries: a review of the effectiveness of tagging systems for library catalogs. Journal of Library Metadata, 13(1), pp.36-58.

Goodman, V.D., 2011. Applying ethnographic research methods in library and information settings. Libri, 61(1), pp.1-11.

Gordon, R.S. \& West, J., 2008. Making search better for patrons. Computers in Libraries, 28(5), pp.54-55.

Gorman, G.E. \& Clayton, P., 2005. Qualitative research for the information professional: a practical handbook 2nd ed., London: Facet.

Griffiths, J.R. \& Brophy, P., 2005. Student searching behavior and the web: use of academic resources and Google. Library Trends, 53(4), pp.539-554.

Gross, J. \& Sheridan, L., 2011. Web scale discovery: the user experience. New Library World, 112(5/6), pp.236-247. 
Haglund, L. \& Olsson, P., 2008. The impact on university libraries of changes in information behavior among academic researchers: a multiple case study. The Journal of Academic Librarianship, 34(1), pp.52-59.

Hahn, C., 2008. Doing qualitative research using your computer: a practical guide, London: Sage.

Hammersley, M. \& Atkinson, P., 2007. Ethnography: principles in practice 3rd ed., London: Routledge.

Ho, B., Kelley, K. \& Garrison, S., 2009. Implementing VuFind as an alternative to Voyager's WebVoyage interface: one library's experience. Library Hi Tech, 27(1), pp.82-92.

Holman, L., Hom, A., Darraj, E., Mathieson, H., Glaser, J., Nettles, D. \& Waller, A., 2012. How users approach discovery tools. In M.P. Popp \& D. Dallis, eds. Planning and implementing resource discovery tools in academic libraries. Hershey, Pennsylvania: Information Science Reference, pp. 252-267.

Johnson, A., 2012. Notes fields and their value to academic library users. Unpublished MA dissertation. University College London.

Johnson, F.C. \& Craven, J., 2010. Beyond usability: the study of functionality of the 2.0 online catalogue (OPAC). New Review of Academic Librarianship, 16(2), pp.228-250.

Kani-Zabihi, E., Ghinea, G. \& Chen, S.Y., 2008. User perceptions of online public library catalogues. International Journal of Information Management, 28(6), pp.492-502.

Keene, C., 2011. Discovery services: next generation of searching scholarly information. Serials: The Journal for the Serials Community, 24(2), pp.193-196.

Khoo, M., Rozaklis, L. \& Hall, C., 2012. A survey of the use of ethnographic methods in the study of libraries and library users. Library \& Information Science Research, 34(2), pp.82-91.

Kirkland, L.N., 2013. The relationship of metadata to item circulation. Cataloging \& Classification Quarterly, 51(5), pp.510-531.

LeCompte, M.D. \& Schensul, J.J., 1999a. Analyzing and interpreting ethnographic data, London: AltaMira Press.

LeCompte, M.D. \& Schensul, J.J., 1999b. Designing and conducting ethnographic research, London: AltaMira Press.

Leebaw, D., Conlan, B., Gonnerman, K., Johnston, S. \& Sinkler-Miller, C., 2013. Improving library resource discovery: exploring the possibilities of VuFind and web-scale discovery. Journal of Web Librarianship, 7(2), pp.154-189.

Liu, W., 2010. Remote users' OPAC searching habits: a comparative case study through web transaction log analysis. Kentucky Libraries, 74(3), pp.6-13.

Luther, J. \& Kelly, M.C., 2011. The next generation of discovery. Library Journal, 136(5), pp.66-71.

Majors, R., 2012. Comparative user experiences of next-generation catalogue interfaces. Library Trends, 61(1), pp.186-207. 
Markey, K., 2007a. The online library catalog: paradise lost and paradise regained? D-Lib Magazine, 13(1/2). Available at: http://www.dlib.org/dlib/january07/markey/01markey.html [Accessed May 13, 2013].

Markey, K., 2007b. Twenty-five years of end-user searching, part 1: research findings. Journal of the American Society for Information Science and Technology, 58(8), pp.1071-1081.

Markey, K., 2007c. Twenty-five years of end-user searching, part 2: future research directions. Journal of the American Society for Information Science and Technology, 58(8), pp.1123-1130.

Merčun, T. \& Žumer, M., 2008. New generation of catalogues for the new generation of users: a comparison of six library catalogues. Program: Electronic Library and Information Systems, 42(3), pp.243-261.

Merkley, C., 2012. Enhanced catalogue records positively impact circulation but are not used to their potential in patron searching. Evidence Based Library and Information Practice, 7(3), pp.73-76.

Mi, J. \& Weng, C., 2008. Revitalizing the library OPAC: interface, searching, and display challenges. Information Technology and Libraries, 27(1), pp.5-22.

Moulaison, H.L., 2008. OPAC queries at a medium-sized academic library. Library Resources \& Technical Services, 52(4), pp.230-237.

Nagy, A., 2011. Analyzing the next-generation catalog. Library Technology Reports, 47(7). pp.5-27.

Novotny, E., 2004. I don't think I click: a protocol analysis study of use of a library online catalog in the internet age. College \& Research Libraries, 65(6), pp.525-537.

Novotny, E. \& Cahoy, E.S., 2006. If we teach, do they learn? The impact of instruction on online catalog search strategies. Portal: Libraries and the Academy, 6(2), pp.155-167.

O'Hara, L., Nicholls, P. \& Keiller, K., 2012. Search success at the University of Manitoba libraries pre- and post-Summon implementation. In M.P. Popp \& D. Dallis, eds. Planning and implementing resource discovery tools in academic libraries. Hershey, Pennsylvania: Information Science Reference, pp. 268-287.

Olson, T.A., 2007. Utility of a faceted catalog for scholarly research. Library Hi Tech, 25(4), pp.550-561.

Othman, R., 2004. An applied ethnographic method for evaluating retrieval features. The Electronic Library, 22(5), pp.425-432.

Philip, M., 2010. Do students want a one-stop-shop to help them navigate their way around the maze of library resources? A usability study looking at the beta version of Summon, the new library search engine at the University of Huddersfield. Unpublished MA dissertation. University of Sheffield. Available at: http://eprints.hud.ac.uk/9824/ [Accessed May 13, 2013].

Pickard, A.J., 2013. Research methods in information 2nd ed., London: Facet. 
Preater, A., 2010. Mental models and user experience of a next-generation library catalogue. Unpublished MSc dissertation. Northumbria University. Available at: http://m.preater.com/wp-content/uploads/2011/12/Andrew-Preater-MScDissertation-final.pdf [Accessed May 13, 2013].

Ramdeen, S. \& Hemminger, B.M., 2012. A tale of two interfaces: how facets affect the library catalog search. Journal of the American Society for Information Science and Technology, 63(4), pp.702-715.

Sadeh, T., 2008. User experience in the library: a case study. New Library World, 109(1/2), pp.7-24.

Salaba, A. \& Zhang, Y., 2009. User perspectives on nextgen catalog features. Proceedings of the American Society for Information Science and Technology, 46(1), pp.1-4.

Sandstrom, A.R. \& Sandstrom, P.E., 1995. The use and misuse of anthropological methods in library and information science research. The Library Quarterly, 65(2), pp.161-199.

Schensul, S.L., Schensul, J.J. \& LeCompte, M.D., 1999. Essential ethnographic methods: observations, interviews, and questionnaires, London: AltaMira Press.

Tam, W., Cox, A.M. \& Bussey, A., 2009. Student user preferences for features of nextgeneration OPACs: a case study of University of Sheffield international students. Program: Electronic Library and Information Systems, 43(4), pp.349-374.

Tedd, L.A., 1994. OPACs through the ages. Library Review, 43(4), pp.27-37.

Thoburn, J., Coates, A. \& Stone, G., 2012. Simplifying resource discovery and access in academic libraries: implementing and evaluating Summon at Huddersfield and Northumbria Universities. In M.P. Popp \& D. Dallis, eds. Planning and implementing resource discovery tools in academic libraries. Hershey, Pennsylvania: Information Science Reference, pp. 580-597.

Thomsett-Scott, B. \& Reese, P.E., 2012. Academic libraries and discovery tools: a survey of the literature. College \& Undergraduate Libraries, 19(2-4), pp.123-143.

Tosaka, Y. \& Weng, C., 2011. Reexamining content-enriched access: its effect on usage and discovery. College \& Research Libraries, 72(5), pp.412-427.

Webb, P.L. \& Nero, M.D., 2009. OPACs in the clouds. Computers in Libraries, 29(9), pp.1822.

Whitehead, M., 2009. Understanding information research to develop new information tools. Presented at BC Library Conference. Burnaby, British Columbia. Available at: http://eprints.rclis.org/13059/ [Accessed July 29, 2013].

Wiles, R., 2013. What are qualitative research ethics? [Ebook], London: Bloomsbury Academic.

Wilkinson, E.H., 2009. Usability and mental models of Google and PRIMO in the context of an academic tertiary library. Unpublished MLIS dissertation. University of Wellington. Available at: https://researchspace.auckland.ac.nz/handle/2292/5173 [Accessed May 14, 2013]. 
Williams, S.C. \& Foster, A.K., 2011. Promise fulfilled? An EBSCO Discovery Service usability study. Journal of Web Librarianship, 5(3), pp.179-198.

Wilson, V., 2012. Ethnography and the catalogue: the potential of an ethnographic approach to studies of library catalogues and their users. Unpublished MA dissertation. University College London.

Yang, S.Q. \& Wagner, K., 2010. Evaluating and comparing discovery tools: how close are we towards next generation catalog? Library Hi Tech, 28(4), pp.690-709.

Yu, H. \& Young, M., 2004. The impact of web search engines on subject searching in OPAC. Information Technology and Libraries, 23(4), pp.168-180. 


\section{Appendices}

\subsection{Appendix A: Illustrations of the Encore interface}

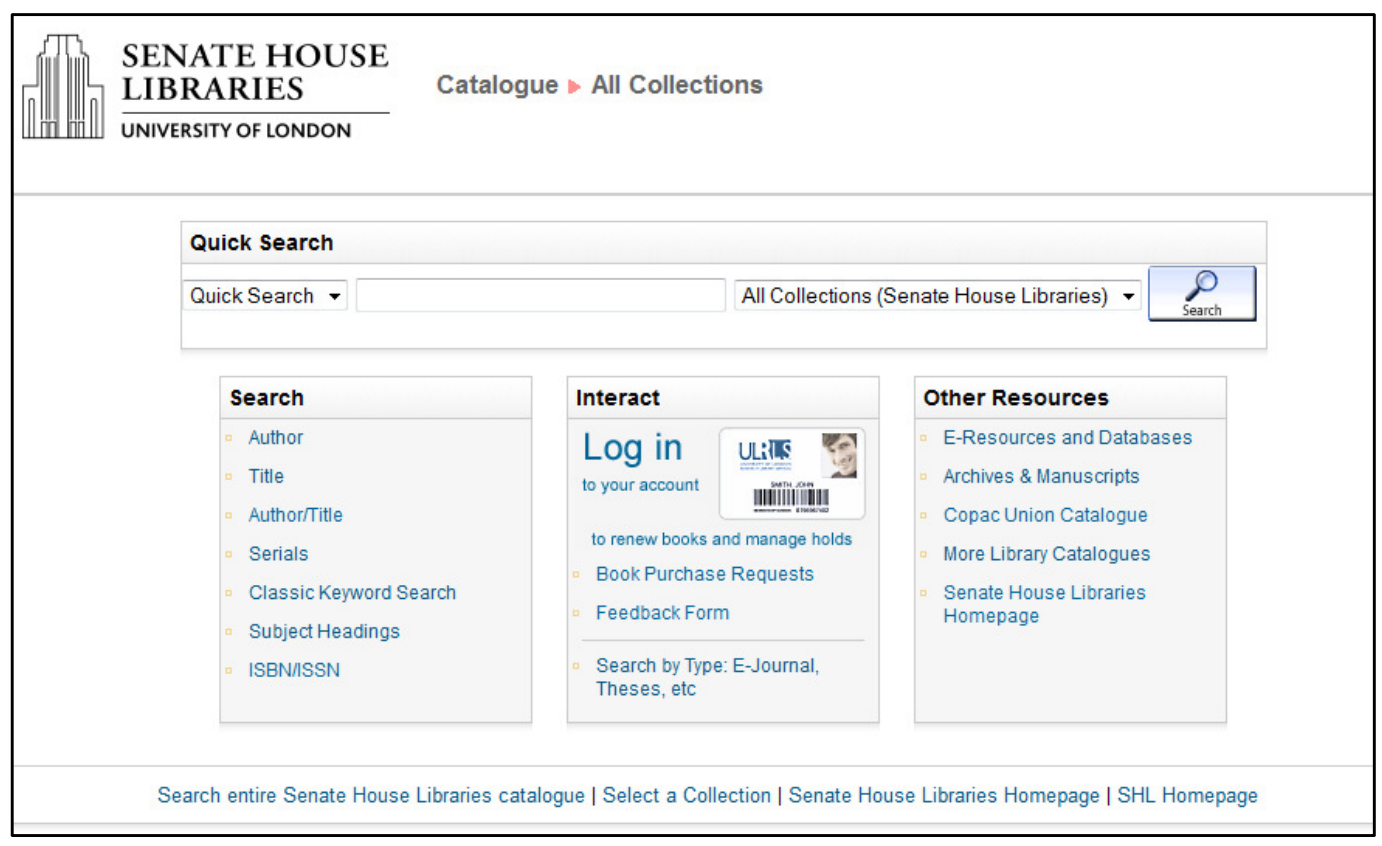

Quick search screen

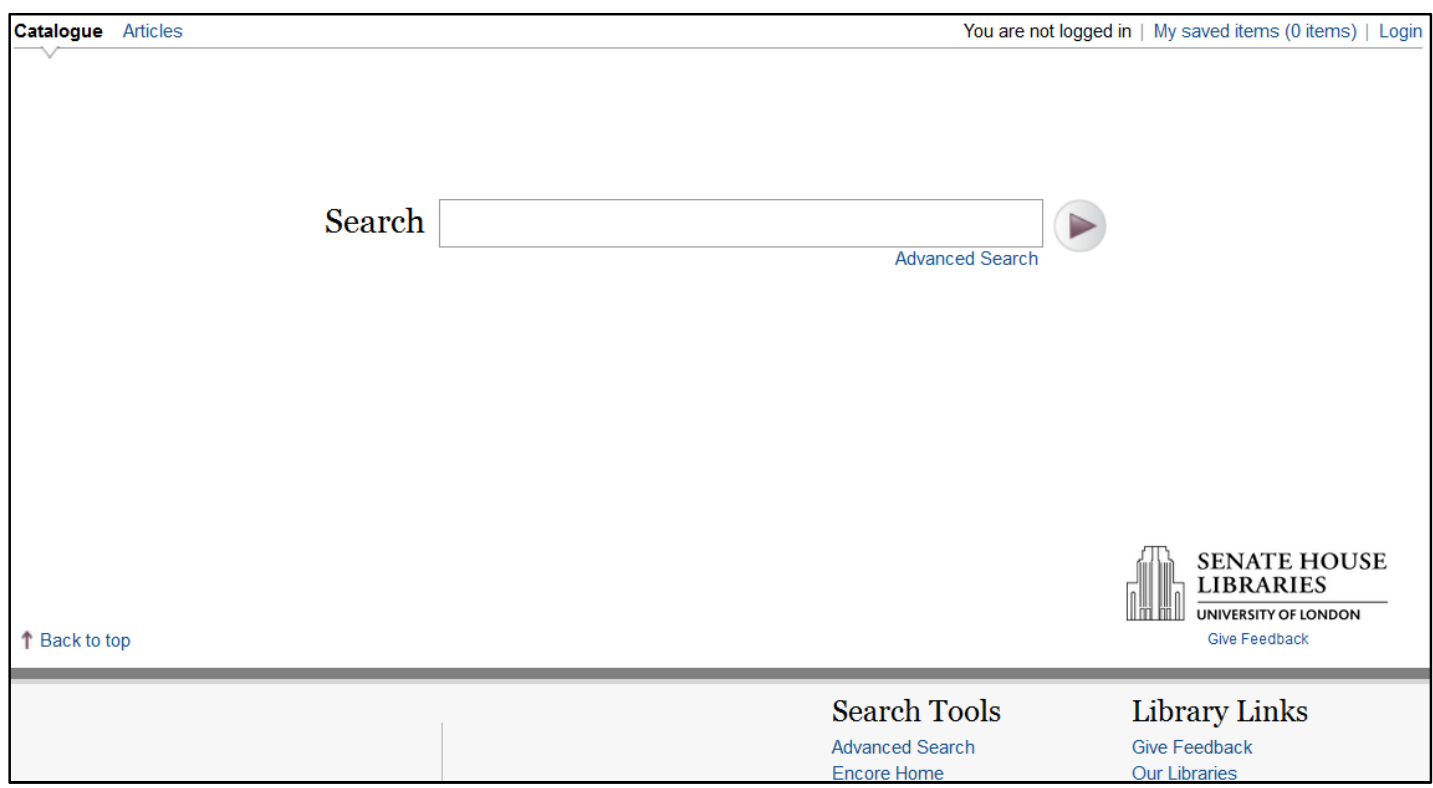

Main search screen 


\begin{tabular}{|l|l|l|l|l|l|l|}
\hline Catalogue & & \\
Advanced Search Basic Search \\
\hline Use the form below to construct your query
\end{tabular}

Advanced search screen 


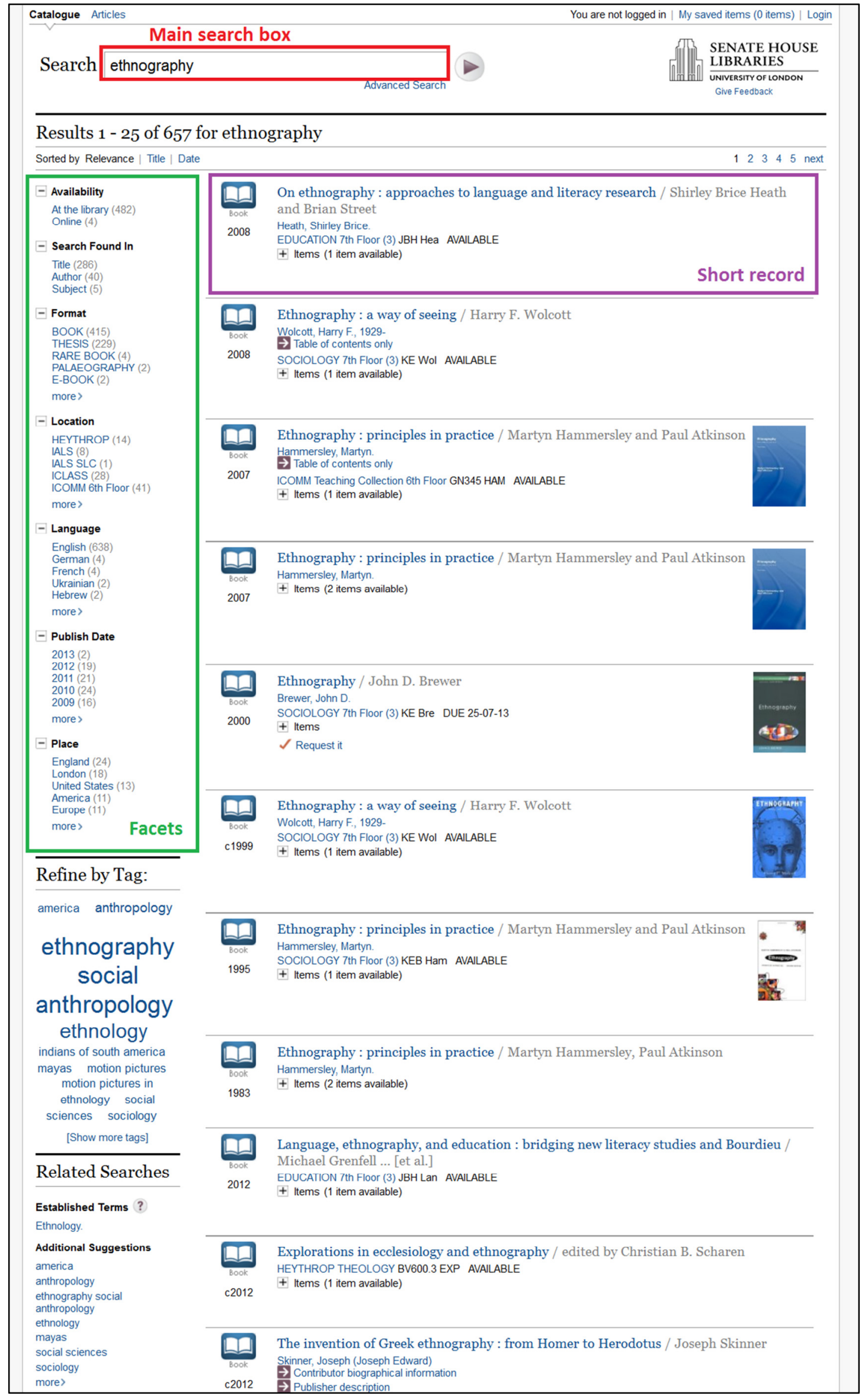




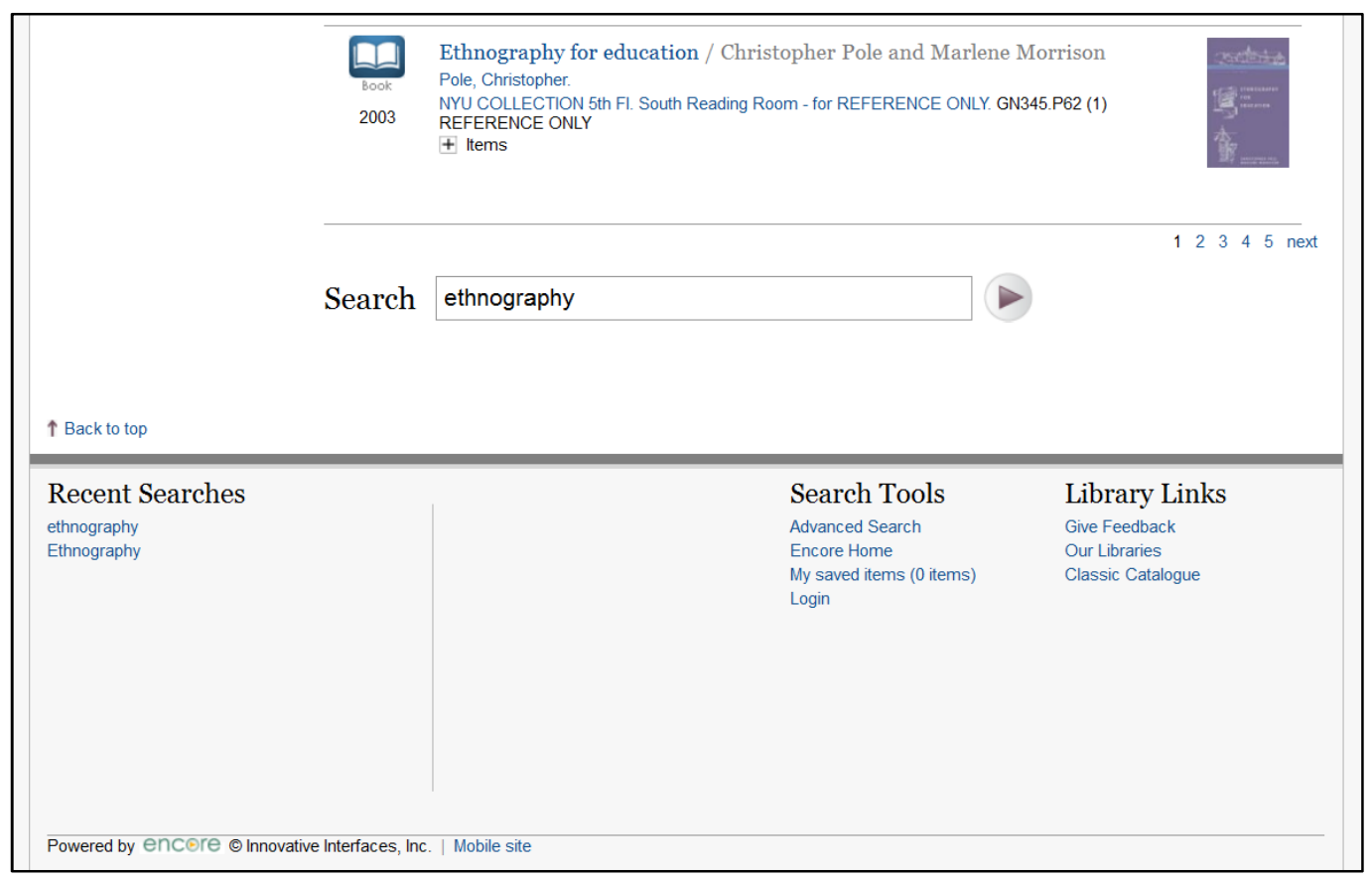

Bottom of results screen

\section{Short record (when cursor is over it) showing outline and the saved / EndNote / RefWorks} toolbar 


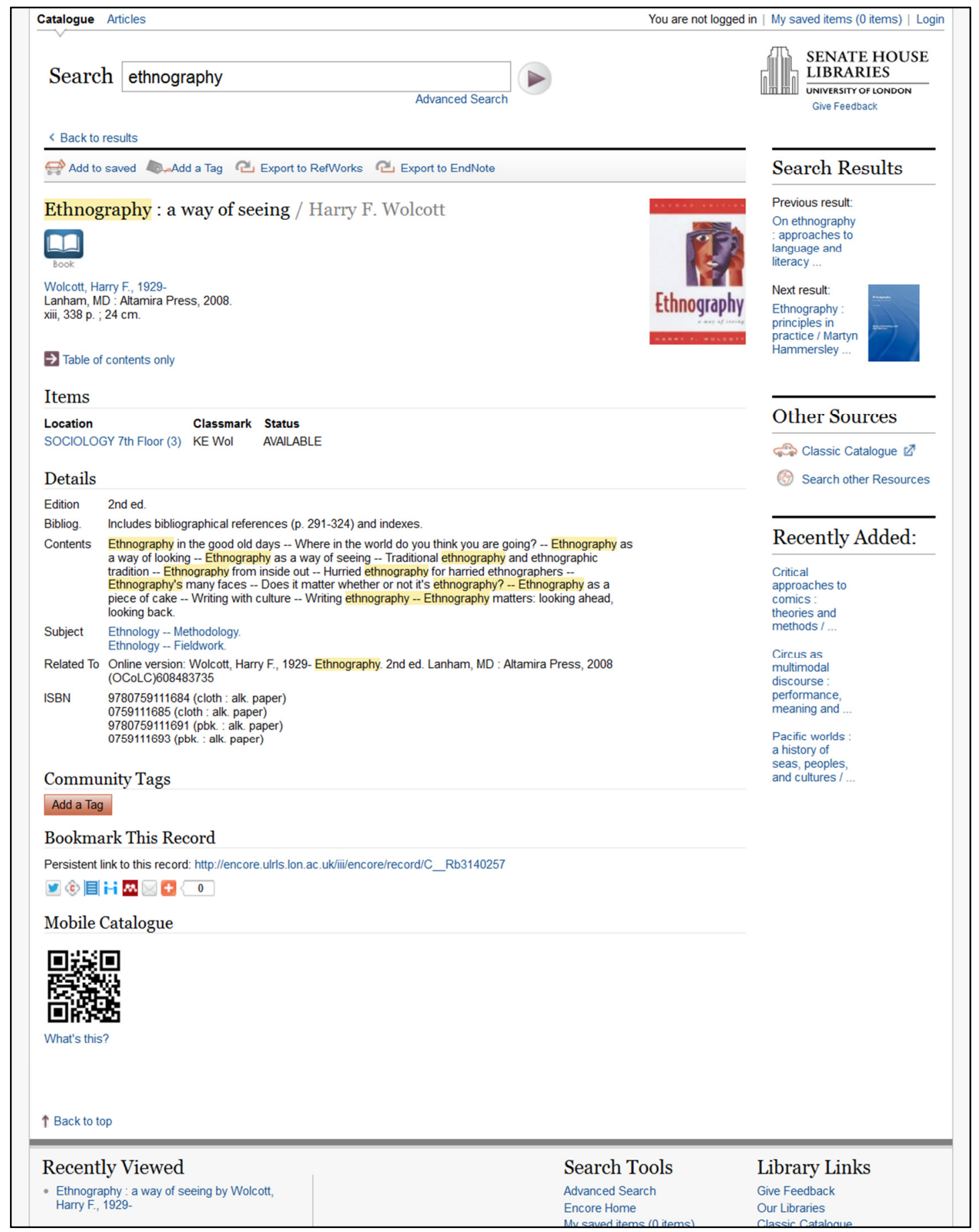

\section{Full record}


INSTG099 Dissertation

Elizabeth Atkinson

58

7.2 Appendix B: Fieldnotes

7.2.1 Example of handwritten fieldnotes

W Information and consent form read and signed

OBSERVATION

Participant: C Date: $4 / 6 / 13$

Start time: 12.07 End time: 12,20

Device: Own Everywhere Type:

Catalogue terminal

another search is shooing contemporary s deleted filipino domestic work one se sulk returned, dicks title tales scrap paper cortes downsomethingt
copies tidily?
sids down, puts hat to modish leans jason han and appears to think

* dicks permanent link

* Writer mare on

scrolls up, pauses

work globalization 
INSTG099 Dissertation

Elizabeth Atkinson

59

Participant

2

leans face on hand.

slow ky scrolls down

uppers to red reading

vans on leg and pullsat lip

pouring ar continuing to sell slow ley underlines + writes more on seep paper looking between screen an cl paper frequently sores cursor so highlights ital

writes a little more

same for another record (but tums over gie ce of pepper as has rem out of space

clicks on next page, stow le sards down, oc cassionally peewsining

stoakips at another ne cord

highlighted (but no moremut of cursor $\downarrow$ writes ceres

continues scrolling 
INSTG099 Dissertation

Elizabeth Atkinson

60

Participant C

3

slops again, rotates paper $\alpha$ taws box + writes scrolls dozen, dicks on title

* mowed cursor over subjecting back

clicks next pa gee

clicks fist title

pauses to bock, tries to hilt comp

* Screen

takes more scrap paper

cortes dow something

back button

scrolls down, pausing

Hressarsor on er title

continues scrolling

leaning face on hand

quickly scrolls dewn/up/down

dick jog 4 
INSTG099 Dissertation

Elizabeth Atkinson

61

Participant C

4

dicks on title

* hovers cursor \& over cover, al text apples

write o something on paper, frequently looking to and from screen.

declares don

interview

Reading list easier

keywords - servants of globular ration subject click ian subject - write morectoron 


\subsubsection{Conventions used}

\begin{tabular}{|l|l|}
\hline This font & The participant typed this \\
\hline Bold & The participant clicked on this \\
\hline Italic & The participant selected this from a list of options \\
\hline "In speech marks" & Direct quote \\
\hline$[\ldots .]$. & $\begin{array}{l}\text { One or more words or sounds have been left out (within a direct } \\
\text { quote) }\end{array}$ \\
\hline
\end{tabular}

\subsubsection{Participant A}

Monday $3^{\text {rd }}$ June 2013

Recruitment method: Approached as initiating search in catalogue hall

\section{Observation}

Time: Morning

Location: Catalogue Hall

Devices: Own MacBook and Catalogue terminal

Search duration: 6 minutes

Participant opens MacBook and opens a word processing document containing a list of references. He spends about 1 minute looking through the document, sometimes scrolling quickly and sometimes reading references, occasionally highlighting one. He writes part of a reference down on a piece of scrap paper he picks up from the scrap paper box.

The participant moves his MacBook and folder to the left of him and pulls the keyboard of the catalogue terminal towards him. He double clicks on the catalogue icon on the desktop and it appears as a broken link. He clicks on start and then Internet Explorer. The quick search screen appears as the home page.

He types william petty treatise into the quick search box and runs the search. He uses the find feature of Internet Explorer to search the results list for 1662. He clicks on the title of an item with the publication date 1662 to open its full record. He quickly scrolls down the record and back up again. He writes something on the piece of scrap paper. He 
types jacob $v$ into the main search box, but does not click search. He looks at the open catalogue record again and writes more on the piece of scrap paper.

He goes back to the main search box and completes the search query he had started so that it reads jacob vanderlint money answers all things. He clicks on the title of one of the results to open its full record. He scrolls down the record and writes something on the piece of scrap paper.

The participant declares that he has finished searching.

\section{Interview}

I ask the participant if the search he has conducted is typical of the sort of search he conducts on this catalogue. He replies that he is a visiting student from Harvard University and that the system there is very different. He continues, by saying that it is actually not very different, but it is not the same, so his search was not typical in the sense that it was not using the system he is used to. I ask if his search was typical for his use of the Senate House Library catalogue and he replies that it is.

The participant was searching for known items during this search. He does not use the Senate House Library catalogue for subject searching because he is doing archival research so he already has a very good idea of what he is looking for.

The participant always uses the main search box when searching the catalogue. He is aware that there are other ways to search stating "I think there are some subcatalogues, but I'm not very aware of how to use them." He is aware of the facets which can be used to refine searches, but does not use them because he can find what he wants quickly without them. I ask about him using the find feature of Internet Explorer and he replies that he used this because he is looking for the books that were owned by a particular person and so needs to 
find the version of the book from that particular year. He thinks that using the Internet Explorer find feature is the easiest way to find the right date.

He is aware that there is an advanced search and states that he thinks he has used it before, contradicting with his earlier statement that he always uses the main search box.

When he was looking at the full record he was looking for a "reference number" to make sure he gets the right book, in case there are many books on that shelf.

\subsubsection{Participant B}

Monday $3^{\text {rd }}$ June 2013

Recruitment method: Approached as initiating search in catalogue hall

\section{Observation}

Time: Afternoon

Location: Catalogue Hall

Device: Catalogue terminal

Search duration: 2 minutes

The screen shows the quick search screen. The participant enters Anne Carson in the quick search box. He scrolls about half way down the first page of results and pauses at one of the results, moving the cursor so that the item is outlined. He gets a notebook out of his jacket pocket and writes down the book and its location. He scrolls further down the page, pauses to look at his notebook, and then scrolls down a little further. He pauses at another record which the cursor is over, looks at it for a few seconds and then writes down its location in his notebook.

The participant scrolls up to the top of the page. He moves his cursor around at the top of the page and appears to be looking for something. He highlights the text in the search box, deletes it and then closes the catalogue window. 


\section{Interview}

This search was typical of the type of search this participant uses the catalogue for. He was searching for a particular book by the author Anne Carson, but thought he might also want some of her other books and wanted to see which of her books the library had.

The participant always uses the quick search box because he just enters an author or a title and "it just functions", so he doesn't see the point in using the advanced search. He has tried using the advanced search before, but wasn't able narrow the search how he wanted to or to quickly find what he was looking for with it. When not using the catalogue terminals he usually uses the search box on the homepage of the library website.

The participant has used the left-hand sidebar when a search for an author's name has retrieved results for several authors with that name. In this case he has used the author facet to refine his search to the author he was searching for.

The most useful information in the record for working out whether an item is going to be useful is whether the item is available and its location (i.e. which library it is in).

He only looked at the short records for items during this search because since he knew what he was looking for, the short record provided all of the information he needed. When he is "in more of a browsing state of mind" he uses the full records.

\subsubsection{Participant C}

Tuesday $4^{\text {th }}$ June 2013

Recruitment method: Approached as initiating search in catalogue hall

\section{Observation}

Time: Morning

Location: Catalogue Hall

Device: Catalogue terminal 
Search duration: 13 minutes

Full record for a previous user's search is showing on screen. The participant types contemporary s into the main search box, then deletes this and types filipino domestic work. One result is returned and the participant clicks on the title, opening the full record. She takes a piece of scrap paper from the scrap paper box and writes down something I cannot see. She scrolls down the page and puts her hand on her mouth. She leans her face on her hand and looks at the record for several seconds. She clicks on persistent link to this record, which reloads the page she is already on. She scrolls down the record again, writes on the piece of paper, scrolls up and looks at the screen for a few seconds.

The participant types work globalization in the main search box. She leans her face on her hand as she scrolls slowly through the results. She stops scrolling and leans on her left leg with one hand and pulls at her bottom lip with the other while looking at a record for several seconds. She continues scrolling down the page, occasionally pausing for a few seconds while appearing to read a record. After one of these pauses she writes more on the piece of paper, frequently looking between the screen and piece of paper.

She moves the cursor so that an item near the bottom of the screen is outlined and writes again on the piece of paper. She scrolls a little way down the page, again a record is outlined (I cannot tell if the cursor was moved), turns the piece of paper $90^{\circ}$ and writes on it again.

She clicks on $\mathbf{2}$ at the bottom of the page to go to the second page of results. She slowly scrolls through these results, occasionally pausing for a few seconds. She stops at another record and writes on the piece of paper. She continues scrolling down. She stops and writes on the piece of paper again. 
She scrolls down further and clicks on a title, opening the full record. She moves the cursor over the subjects and looks at the screen for several seconds. She clicks Internet Explorer's back button, which takes her to the list of results. She clicks on $\mathbf{3}$ at the bottom of the page, which takes her to the third page of results.

She clicks on the title of the first item on this page to go to the full record. She pauses for a few seconds looking at the screen and moves her right hand so that it is under the bottom right corner of the computer monitor. I cannot see if she is pressing any buttons. She takes another piece of paper from the scrap paper box and writes something on it. She clicks on Internet Explorer's back button again to return to the results list.

She scrolls through the results list, occasionally pausing and leaning her face on her hand. When part way down the list of results she quickly scrolls down, then up and then down again. She clicks on $\mathbf{4}$ to go to the final page of results. She clicks on a title to go to the full record. She moves the cursor so that it is over the cover image and the alt text (the title and statement of responsibility) appears. She writes something on the piece of paper, again frequently looking from the piece of paper to the screen and back again.

The participant declares she has finished searching.

\section{Interview}

The participant states that the search she has just conducted is typical of a search she usually conducts on this catalogue, but that it is easier when she has a reading list. When she has a reading list she knows exactly what she is looking for, but in this case she was searching for information on a topic rather than particular items and "it was more of a looking for keywords".

I say that I noticed at the start of her search she started typing something, and then deleted it and typed something else instead. I ask why this was. She says that she started by typing 
in exactly what she was looking for, but then realised "you can find what I'm looking for by typing something else in". I ask her to clarify this and she says she decided to use words that come up more in titles of books. She says she is looking for information on "women and domestic work, especially in the global context and also contemporary slavery".

When I ask whether she was looking for specifically for books or articles or something else today, she initially says it doesn't matter whether it's books or articles. Sometimes she looks specifically for articles because she can take them with her and read them at home. Then she says today she was specifically looking for books because she wants to take some books out - contradicting her initial statement. "Sometimes when I look for something and it gives me articles I find that to be a bit more useful for me. I like that more."

If she needs information on "a very lofty sort of subject" she looks for books that are more general to help her understand the subject in a broader sense. I ask for an example and she says if she were doing an essay on the philosopher Foucault, as well as looking for Foucault she would look for his critics who "would explain his theory in a more approachable way" and perhaps a sociology anthology.

The participant found what she wanted to find, including an item which she didn't know existed but is extremely useful and she "would definitely like to find".

The participant usually starts her search in the main search box. She knows there is the option of advanced search and has tried using it, but she says "maybe I don't know how to use it very well [...] I find it confusing". She tells me sometimes things she knows should be there do not come up even if she types it in, "but I might be wrong".

I ask if the participant is aware that the catalogue includes items in other locations. She says that she is, but that "I only think about that when I see a book I would like to get here and it is somewhere else and I know I have very little time and I can't go and get it from there". I 
ask if she is aware of how to refine her search so that it only shows items that are in Senate House Library. She says that she isn't and I ask if she has noticed that left-hand sidebar. She says that she has, but "I guess I always ignored it" - she has never used the facets to refine a search.

She finds that being able to download articles is useful, and thinks that this is a new feature of the catalogue. She says that she has just noticed (while we have been speaking) the recent searches feature and thinks that it could be useful.

I say that I noticed that at one point she clicked on a persistent link while in a full record and ask what she was expecting from it. She says "you know on Amazon when you click sometimes it just gives you a table of contents and a few pages of it. I guess I was expecting that. Very foolish in fact, of course it wouldn't."

I ask what she was writing down on the pieces of paper and she says that she was writing the name of the book, sometimes the author, where to find it and the reference. She is showing me what she has written as she says this and "where to find it" is what is termed location in the catalogue (e.g. HISTORY OF SCIENCE $7^{\text {th }}$ Floor (3)) and when she says "reference" she is pointing to the classmark.

The participant finds the subjects listed in the full record useful for making it clearer whether the book is something she is looking for or not.

I ask what she finds the most useful piece of information on the record and she says that "sometimes it's very easy and you get it very, you know from the title of the book you understand clearly that it is what you want but what I find very, very useful is the table of contents". Sometimes the whole book might not be useful, but one chapter of it is.

I ask about when she appeared to be touching the bottom on the computer screen but she does not remember doing so and thinks she was just moving about. 
I say that I noticed at one point she moved the cursor over an image of a book cover and text appeared. I ask if that was intentional and whether she was expecting anything. She says it was not intentional. She says "it is a bit nicer when you see the book cover, I don't know why. And some books have it, some books don't".

I ask if there is anything about the catalogue she finds confusing and she says "I don't think I find anything particularly confusing". I probe further asking if there is anything she finds a bit confusing and she says "I guess sometimes I expect it to get it the first time. For instance, when I'm looking for something specific, but obviously it's not in the database so it can't really find it. So, I get that." She clarifies that this is when she is searching for items that turn out not to be in the library and says this isn't really something that is confusing, it's another issue. "It would be nice if it could direct you to somewhere else where you could find that. Maybe online, or maybe a different library."

She tells me that she finds having a search box that searches the library catalogue on the library website homepage counterintuitive - she expects to have to go somewhere else to get to the library catalogue. She says that she does use the catalogue search box on the SHL homepage, and "I think it's very good". I point out the catalogue tab on the SHL homepage and ask if she ever uses that to access the catalogue. She seems uncertain, but says "there is part of me that feels I should go to the catalogue tab".

She tells me that in the full record for items, "I very often look at the keywords" and from them she can tell whether the item is relevant to her research. I ask her clarify what she means by keywords and she opens a record and points to the subject headings. "I think that's useful. Yeah, I think that's very, very useful." I ask if she is aware that if she clicks on a subject it will take her to all the records with that subject. She says she hasn't done that before, then clicks on one of the subjects in the record she opened. She says "No, I didn't 
know that" and looks at the three results shown. She says "Ah, that is very interesting" and writes down the location and classmark of one of the books in the list.

I ask if there is anything else about the catalogue she would like to mention and she tells me that she "is very happy with the catalogue" and has been using the library for five years. She finds the library a nice space and, although she can't always find everything she wants, she finds the catalogue useful.

\subsubsection{Participant D}

Tuesday $4^{\text {th }}$ June 2013

Recruitment meth: Word of mouth

This participant is a a full time student on the UCL MA in Library and Information studies.

\section{Observation}

Time: Afternoon

Location: Catalogue Hall

Device: Catalogue terminal

Search duration: 12 minutes

Quick search screen shows. The participant clicks on the Log in link and logs in. She clicks the Checked out items button and when the list appears clicks on Renew all. She clicks on the Catalogue link at the top of the screen, then Begin your search, this takes her to the quick search screen. She types miniature books and presses enter. She scrolls down the results list, pauses at a record, moves the cursor around the record and then clicks on Request it. A pop up appears with the title and statement of responsibility, a list of items that can be requested for that record (in this case there is only one) and a box in which the user can enter any additional information about their request. The participant clicks on the Submit button on this pop up. A message stating "Your request for [...] will be available to 
collect from [...]" appears and the participant closes this. She writes down the title and classmark of the book on a pad of paper she has with her.

The participant slowly scrolls down the list of results. She clicks Request it for another item, then Submit on the pop up that appears and then closes the message stating when and where the item will be available to collect. She writes the title and classmark of the book on the pad of paper.

She scrolls down and then back up the page quickly. Under the Refine by Tag section she clicks on miniature books. She slowly scrolls down the list of results that this brings up. She moves the cursor over the record for an item and then writes something in the notepad (this record does not have a Request it link).

She scrolls slowly down the page and clicks on $\mathbf{2}$ when she gets to the bottom of the page to be taken to the next page. She moves the cursor over the facets in the left-hand sidebar and scrolls down. Under Refine by Tag she clicks on the cross symbol next to miniature books which removes this requirement from the search.

She scrolls down the page. She moves the cursor over to the Refine by Tag section and pauses with it over the tag 'auction catalogs', appearing to consider whether she should click it. She clicks on [Show more tags] at the bottom of the Refine by Tag section. This brings up a pop up with a much larger number of tags. She scrolls down this pop up slowly and spends several seconds looking at it. She closes the pop up, quickly scrolls up to the top of the page and clicks on Advanced search.

This brings up the advanced search with her search for miniature books already in the first search box. She deletes the word books and leaves the drop down menu for the term miniature as Keyword. She selects Author from the drop down list for the next search box, leaves the Boolean connector as AND, types Spielmann and presses enter. This 
retrieves two results. She moves the cursor down the page over the two results and pauses for a few seconds, then clicks on the Internet Explorer back button. This brings up the advanced search screen.

She searches for catalogue as a Keyword and Spielmann as Author, connected by AND. She slowly scrolls down the one page of results this search retrieves. She clicks on the Internet Explorer back button, returning to the advanced search page, again showing her original search forminiature books as a keyword.

She opens a book she has with her which has references highlighted with sticky index tabs (small transparent post it notes). She searches for Pryce and publisher, both as Keywords, but in separate search boxes and, again, leaving the Boolean connector as AND. This search just brings up a "No catalog results found. for (Pryce) (publisher). Did you mean: ...?" and she immediately clicks on the Internet Explorer back button.

She conducts another advanced search using miniature as a Subject in one search box, connected by AND to type in the second search box, for which she selects Keyword. This retrieves two results and she clicks on the title for one of them to open the full record for it. She does not look at this record for long before clicking on the Internet Explorer back button, taking her to the list of results. She clicks back again to return to the advanced search page.

She conducts an advanced search for Subject miniature AND Keyword typefaces. No results are found and she immediately clicks on the Internet Explorer back button.

She conducts an advanced search for Subject miniature AND Keyword font. No results are found and she immediately clicks on the Internet Explorer back button.

She flicks through the book with the highlighted references. She conducts an advanced search for bi jou a lmanac, leaving the drop down as Keyword. She clicks on the title of 
one of the results to go to the full record for the item. She scrolls down the record and then clicks on the Internet Explorer back button. She writes something down in her notepad and then clicks of Add to saved in the saved / EndNote / RefWorks toolbar.

She clicks on the Advanced search link at the top of the page and conducts an advanced search for Keyword travelling library. When the results are displayed she immediately clicks on the Internet Explorer back button.

She amends her search to "travelling librarian". This brings up a message saying “No catalog results found. for ("travelling librarian"). Did you mean: traveling libraries?". She clicks on traveling libraries (which is a link to this search) and spends a few seconds looking at the two results this retrieves. She clicks the Internet Explorer back button, returning to the advanced search page.

She conducts an advanced search for Keyword microscopic AND Keyword type. No results are returned and she clicks the Internet Explorer back button several times until she reaches the main search page. She then clicks on Advanced search.

She conducts an advanced search for Subject book studies AND Keywordminiature. No results are found and she immediately clicks on the Internet Explorer back button.

She conducts another search, but too quickly for me to see what she types and quickly scrolls down the page. She scrolls past the list of results to the Related Searches section at the bottom of the left-hand sidebar. She clicks on medieval illumination of books and manuscripts. She scrolls down the list of records this brings up. She stops and writes down the title and location of a book in the results list. She scrolls further down the page, although not to the bottom, and then declares that she is done searching. 


\section{Interview}

I ask the participant if that search was typical of the type of search she does on the catalogue, and she states that yes it is, but "it was more of a browse search. Sometimes I know what I'm after". She gives the example of the book she has with her which she was looking in during searching, saying that when she was looking for it "I went in and typed in the title and the author". I ask her what she was using the book for during her search and she tells me that she wants to search for some of the items in the bibliography, but in this search she was using the items in the bibliography to give her ideas for alternative keywords to search for.

The participant tells me that in the Senate House Library catalogue she will always search in one of two ways - by using keywords for a subject search as she did in the observed search, or by searching by title and author for a known item. However, she says she uses other library's catalogues in different ways. For example she "would select by resource type" or in UCL's catalogue she "would go with search the catalogue only, so that I can create a more relevant search". I ask why she doesn't do these things with the SHL catalogue and she tells me "I'm not particularly familiar with this catalogue [...] it's only the fourth or fifth time that I've used it [...] I need to play about with it a bit more".

I ask about the facets in the left-hand sidebar and she tells me that she has used them before. She will sometimes refine by date or language.

I ask if she found what she wanted today and she answers "Yes and no. I was basically having a look to see what the library has on my subject and I have requested a couple of books and I've noted down some titles that are reference only that I will come in and have a look at [...] but I was after something on a specific publisher but it doesn't have it." She clarifies that she wanted books about the specific publisher, rather than books published by them, but when she searched "it told me "Did I mean Prince?" No". 
I ask about where she starts her search. "If I just want a broad idea of what titles are coming up I'll go with the quick search. If I want to increase the specificity I'll go into advanced search [...] I often do that if a quick search is just coming up with useless information." I ask about what route she uses to get into the catalogue when not using the catalogue terminals, and she says she can't remember, but she is aware there are different routes into the catalogue.

"I find the tags helpful, especially the way they increase in size for the more books, or the more items they have on that topic." Also being able to specify the language as English is useful. She would prefer being able to keep her saved searches after she has logged out, instead of just for the duration of the log in session.

I ask what information in the record she finds most useful. She says "For something that I am searching for it would be author, title, shelfmark or whether it's requestable." Also, where there is more than one edition of the book, she uses the dates of publication and edition statement to determine which is most recent or published in the time period she is looking at.

I ask if there is anything the participant finds confusing about the catalogue. She tells me that "I think in bits it can be hard to access from home [...] getting to the Senate House website itself is irritating [...] I noticed a couple of times, the last few times when l've tried to search at home it's crashed or come up with an error message [...] it wouldn't let me renew books or anything, so I was thinking it's a temporary error but that put me off."

The participant likes that the catalogue is "blue and, sort of, off-white, rather than stark black and off-white because it doesn't hurt my eyes as much".

I ask if the participant has any suggestions for improving the catalogue and she says that making the Recent Searches more obvious would be good, because she forgets to look at it. 


\subsubsection{Participant E}

Tuesday $4^{\text {th }}$ June 2013

Recruitment method: Twitter

\section{Observation}

Time: Afternoon

Location: Catalogue Hall

Device: Catalogue terminal

Search duration: 2 minutes

The participant types defoe tour in the quick search box on the quick search screen. An autocomplete pop up appears and the participant mutters to himself "For God's sake". He closes this and the results of the search are shown. He clicks on the title of one of the results to show the full record and spends a few seconds looking at it.

He types description and travel into the search box and runs the search. He uses the facets in the left-hand sidebar to refine his search to Senate House Library under location, Book under format, English under language and England under place. He scrolls down the page of results this returns fairly quickly and then clicks on the more $>$ link under the place facet and selects Great Britain. He scrolls down the page and clicks on the title of a book, opening its full record. He scrolls down the page and clicks on the subject Literary journeys -- Great Britain. He scrolls down the short page of results (eight items) and then announces that he has found what he wanted.

\section{Interview}

I ask if the search the participant has just conducted is typical of the sort of search he usually does on this catalogue. He answers that usually he searches by author and title - "usually I know what I want or I would quite often use a different catalogue to this one to refine first". I ask what catalogues he uses and he replies that he uses "other library catalogues" or the 
Bibliography of British and Irish History. He says "I don't really like this interface very much, I don't use it for very advanced searching", pointing at the computer screen. On this catalogue when searching for a known item he usually uses the author's surname and a relatively uncommon word from the title as search terms.

He tells me a bit about the search he has just conducted. "I'm interested in travel writing in the $18^{\text {th }}$ century in England, about England, so I thought I'd start with Defoe and work out how that was described in the catalogue." I ask if he found what he wanted and he answers that "it's hard to know what you didn't find that you did want" but the items which he did find are the kind of thing he was looking for. He says that eight [the number of items he found] is a bit low and he was expecting to find more.

The participant tells me that he quite often uses the refine option to see whether an item is in the IHR [Institute of Historical Research] library or whether he has to "go upstairs" [i.e. to Senate House Library] to get it. He tells me that he uses the databases, "but really keep it pretty simple, I don't really do much complex searching. [...] Occasionally I'll go back to the old catalogue, the old classic catalogue to do the complex searching cos it's better. But I find this quite good for a quick Google-type search, but not much else." I ask if he ever uses the advanced search and he says "No, I tend to refine afterwards or go to somewhere else if I want to do something advanced".

I ask the participant about the refine options in the left-hand sidebar and he tells me that the location is the most useful - particularly the numbers indicating how many items are in that location. He tells me he doesn't find the tags or related searches useful, so "there's room here for more facets to come down the side". He would like a facet with the date range covered by the subject of the book. 
He tells me he would really like to be able to save searches on his record permanently and to have a way of permanently saving a "book list".

I ask what information in the record he finds most useful and he tells me "One good thing about this catalogue is it does tell you about availability straight away. Other ones you have to go through, maybe two screens." He tells me he finds it confusing when a record in a list of results has multiple items available. "Sometimes you get five items, but l've never really quite worked out why they do that, why they don't split them out."

He tells me there isn't much he would go into the individual record (meaning the full record) for. As he is telling me this he opens the full record for an item. He points to the section of information below the book icon in the full record (author, publication details and physical description) and tells me "I do not use this kind of stuff". I ask if he has noticed any records with a table of contents and if he would find that useful. He has noticed it, but would only find it helpful in a collected volume and would normally prefer to get the book. I ask about the list of subjects in the record. He tells me "I've noticed it, I couldn't say I find it really useful [...] sometimes if you're a bit unsure about the book it does help you get an idea. Generally I know what the book is, good enough anyway. I'd rather read it."

I ask if there is anything else about the catalogue he finds confusing. He tells me "I know this isn't part of your thing, but my main complaint is that I can never find where they've put the databases when I need to." He says the catalogue "is ok, but it's a bit too simple I suppose, rather than being too complicated". I ask how it could be improved. He turns to the computer and goes to the main search screen. He says he would like some facets here, the main thing being he would like to be able to choose which library to search on this page. He says it would also be useful to be able to choose 'book' at this point too, "I sometimes get annoyed if, not annoyed but disappointed if it turns out to be an electronic version of the book you can read online, but there's no physical book in the collection. I find that a bit 
disappointing. I'd rather be able to exclude that from my search first up." He would also like to be able to choose books that are for loan, rather than reference only - he is not sure if this is one of the facets that is currently available to refine searches by.

I ask if there is any other way the catalogue could be improved. He tells me "Having the facets first would be my main thing and, actually, my really big complaint is that I can't save all my searches forever. I can't think of anything else. It works ok. I'd sort of say it's middleing as a catalogue." I ask if there is anything about other catalogues he uses that makes them good and he says that they have a book list function and they have book covers - he says he doesn't think you can get covers on the Senate House Library catalogue. He finds book covers useful because "sometimes you think 'Is this the edition I read before?' and you recognise - you just know it was or it wasn't. That kind of thing." He thinks some other catalogues have better links to "things like the British Library catalogue or other databases", which can be really helpful, to get to another description of the item. "Maybe you can do that from here, but I haven't noticed it."

\subsubsection{Participant F}

Wednesday $5^{\text {th }}$ June 2013

Recruitment method: Twitter

\section{Observation}

Time: Morning

Location: Sterling Library Reading Room

Device: Own MacBook

Search duration: 9 minutes

The participant opens Google Chrome and clicks of a favourites link to the quick search screen. She types economics of leisure into the quick search box. When the results load she scrolls a little way down the page and then back up and looks at the top left 
corner of the screen. She pauses for a moment and then clicks on the title of one of the results to open the full record. She spends a few seconds looking at the screen and then scrolls down the page. She clicks on one of the subject headings and then scrolls down the list of results this brings up. She moves the cursor over the title of a book and pauses for a couple of seconds. She then moves the cursor over the saved / EndNote / RefWorks toolbar at the bottom of the short record. She clicks on the title of this item to go to the full record. She clicks on one of the subjects listed in the full record and this brings up a message saying no catalog results have been found. She sighs and clicks the browser back button. The subject she clicked was an unusual looking one (-- 21000 work -- 21000 leisure -- 20030 work \& leisure -- 20020 -- 31030 social aspects). She looks at the record for a few more seconds and then clicks the back button again to return to the results list.

She slowly scrolls down the page of results, pauses and clicks on another title. She scrolls down the record and clicks on a subject again, this time recognisably a Library of Congress subject heading. She spends a few seconds looking at the list of results this brings up and then clicks on the Advanced search link at the top of the page.

She types prices into the first search box, leisure into the second box, leaves both as Keyword searches linked by AND and clicks on search. This retrieves no results and she clicks on the browser back button. A pop up asking if she wants to confirm resubmission of information appears; she sighs and clicks ok. This brings her back to the advanced search screen. She looks up and out the window for a few of seconds.

She conducts an advanced search for Keyword consumers AND Keyword leisure. She clicks on the title of an item near the top of the list of results retrieved. She scrolls down and looks at the table of contents which is included in this record. She clicks on the browser back button to return to the list of results. 
She scrolls down, moves her cursor over the tags listed in the Refine by tag section in the left-hand sidebar. She clicks on the tag consumers, which brings up two results. She clicks on the Advanced search link at the top of the page.

She conducts an advanced search for Keyword leisure AND Keyword economics. She scrolls down the page and then clicks on recreation in the Refine by tag section in the lefthand sidebar. She clicks on the title of an item and looks at the record for a few seconds. She turns to me and says that usually at this point she would stop and request this item, but she isn't going to do this right now. I ask if she has finished her search and she says she hasn't.

She clicks on the browser back button, which takes her to the advanced search screen. She opens the format drop down list, looks at it for several seconds, clicks somewhere else on the page which closes the drop down list, and then opens it again. She selects E-JOURNAL from the list and runs the search (still Keyword leisure AND Keyword economics). This brings up a message saying "No catalog results found".

She clicks on Classic Catalogue under the Library Links section at the bottom of the page. [at least one step is missing here] She selects SUBJECT from the drop down list to the left of the search box, types economics in the search box and selects E-resources from the drop down on the right of the search box. The results are presented with the Classic Catalogue interface. She scrolls slowly down the list of results and clicks on the title of an item. She clicks on the browser back button. She clicks on another title and, again, quickly clicks on the back button. She sighs and rests her face on her hand.

She types leisure into the search box and selects a title in the list of results that this search retrieves. She clicks on the browser back button twice and clicks on a title in the list of results that is now showing. She is too quick for me to see which search this is. 
She selects TITLE from the drop down list to the left of the search box, types j stor into the search box, selects E-resources from the drop down list to the right of the search box and runs the search. This retrieves two results. She spends a few seconds looking at the screen and then clicks on the second result. She clicks Access onsite in Senate House Libraries under Connect to web resource and completes her log in details on the form that appears.

She runs a short (less than a minute) search in JSTOR, opens the pdf of an article and then turns and says to me that at this point she would stop and read this article.

\section{Interview}

I ask if that search was typical of the sort of search the participant would conduct on this catalogue. She replies that it was very typical, "the untypical would be I know a book, do they have it, either yes or no [...] that doesn't always work because I sometimes do know that it's there but it's so un-Google-like in that it's not forgiving of bad spelling [...] l'll give you a for instance. Today l'd been needing to consult Chambers Journal which is spelt c-h-am-b-e-r-s-apostrophe-s - Chambers's Journal - but because l'd missed the apostrophe-s off when looking for it, it wouldn't find it at all for me and I knew it was there because I'd got a reference that I'd consulted before. So I put Chambers Journal or something in, and because I'd missed the apostrophe-s off, it didn't come back like Google would and said "Do you mean Chambers's Journal?" It just said "not found". So I find that quite irritating [...] I would quite like a "Do you mean?"”. I ask if she has ever noticed a "Do you mean?" in this catalogue and she says "No, I don't think they do it." I tell her that when using keyword search the catalogue does have a "Do you mean?" function and she tells me when searching for a title she will always specify that the search terms should be in the title. "Sometimes I go via Copac because I find that finds things better [...] it just picks them up better. So if I know 
a thing's here and I can't find it I go into Copac and it finds it straight away. It's not really a very good way of doing it, but that's how I do it".

The participant usually uses the quick search at the start of searching, but sometimes goes straight to the classic catalogue "to get myself to a better search".

She tells me that her search today "was a bit frustrating in that until I read the article I finally found I'm not sure if I found the right thing". She explains that she was looking for prices of leisure items in the Victorian times. She tells me "If I'd been doing it better I'd have done a mind map [...] but I didn't, I went straight into prices and leisure and perhaps that was the wrong thing." She was expecting to find something in the economics library with statistical data on her topic. She wasn't bothered whether the information was in an article or book. If, when she reads it, the article she found does not have the information she is looking for, she will continue searching.

"I found it a bit frustrating when it just has a title and an author and you have to click on it to find the subjects because I often find if I find something looks vaguely correct I can go in and find the Library of Congress subject heading and clicking on that, that does find me things quicker. What I don't tend to do is go down that side, you know, the web 2-ish side because it would be much more useful to me if those tags were higher up because I often forget to go to those tags, but they are useful. But in a laptop it's hidden down the bottom and what might be a useful, helpful thing is hidden and perhaps you never go down that far to see it [...] rather than what library do you want to search at - that's not relevant to me." I clarify with her that she is talking about the tags in the Refine by tags section. I ask if she uses any of the other refine by options in the left-hand sidebar and she says "I do, I very often, because I find it incredibly difficult to find online resources in [...] this new catalogue. There used to be a brilliant way of doing it before where the subject librarians would do a subject guide and say here's some handy resources if you're in our subject. Particularly for me, I'm 
not an economics student I'm an arts student. But today I need some economic data." The participant tried to find an economics database using the catalogue, but "I couldn't do that at all. It was total failure." In her own subject she knows what the online databases are, but in other subject fields she doesn't know the title of online databases "even though I'm a librarian I'm not up-to-date, you know things change so much". She tells me "I typed in economics and asked for e-journals and I just got a list of subjects, none of which were helpful. And I miss that subject librarian's guide to resources and I'm sure if I'd been able to go straight to an economics database, rather than trying to find it via books - because that's where I find it. So I did find it via JSTOR, but it's a very old article which is what JSTOR, you know, concentrates on. [...] I cannot find online databases, I know they say it's meant to be simple, but I cannot find them anymore. I don't know how to find them. There used to be an easy way and there isn't anymore. It's a complete mystery to me."

I ask the participant what made her decide to change to using the advanced search part way through her search. She tells me "I needed to refine by format and to be able to do an AND Boolean search." I ask if she ever uses any of the options in the left-hand sidebar to refine her searches. "Occasionally, but I suppose I'm very old school, I like to see it on the screen." I mention that I noticed at one point in her search she was hovering over the Add to saved toolbar (the saved / EndNote / RefWorks toolbar). I ask if she ever uses any of the features in this toolbar. She tells me that she regularly uses the Export to EndNote feature, but that it is "tricky" and "it doesn't work seamlessly, like every other library works seamlessly. You've got to specify a format or something". She prefers to go to Copac and export the records from there to EndNote because "it's so much simpler". She tells me that she doesn't use the "save to my searches, I've never managed to get that to work. I've saved things and they're not there so I've just given up on that." I explain that it only saves items for the current 
search session, and she says "Well, that's quite irritating. Cos I know the British Library have changed so that now you can save it forever and that's much more useful."

I say that I noticed at the start of her first search she was looking around at the top of the screen. I ask if she remembers if she was looking for something particular. She tells me that she was trying to decide whether she should select the online option [under the availability facet] at that point, but "I decided not because it was only giving me one option and I thought no, not enough options, so I stopped. But I often do go in the online one." I ask whether, when using advanced search, the participant ever searches for any of the options other than Keyword. She tells me that she knows that they are there. "What would be so useful for me would be to have a drop down with Publisher, because I thought there used to be one, but I could be wrong, but that in my book studies not being able to search by publisher is a nightmare [...] One of my main publishers I'm researching is a name called Strange, William Strange. And you put Strange in and it's useless [...] I can't find what he publishes. [...] It's possible there's a way I could do it that way, but I've never found a way of searching by publisher that I know of."

I ask why the participant chose to go to the classic catalogue part way through her search. She tells me "because I found the old one so much easier to use than the new one." She hadn't found what she wanted and she tells me she always had more success with the old catalogue than the new one. I ask if there is anything particular about the classic catalogue that makes it easier for her to use. She says "I think both have got advantages. I do like that left-hand column thing, although sometimes I worry that it's filtering and I'm losing stuff because suddenly you can go from 53 down to 9 and I think, ooh actually some of those 53 might have been useful, have I filtered too strictly." This is because she thinks there is missing data in the catalogue records. "I did have lot of confidence in the old catalogue. It never failed me and perhaps that's why I go back to it." 
I ask if there is anything she doesn't like about the classic catalogue. She tells me that she preferred the old website and since the recent changes finds it "incredibly difficult to use. Sometimes I can't even find the website, let alone the catalogue." I ask how she usually gets to the catalogue and she tells me that she has a "permanent tab on my webpage [...] because that's the only way I can be sure of quickly getting to it." She tells me that sometimes searching for Senate House Library brings up a "publicity page and these are all the libraries in Senate House and this is what they do", but she can't find the catalogue. She says the catalogue "is probably down the bottom somewhere, but it shouldn't be. The catalogue is the most important thing of the library and it shouldn't be hidden behind publicity about the place." I ask if she is aware of the catalogue search box near the top of the Senate House Library homepage, and she says "possibly, but that's too small. I want to see a thing that looks like a library catalogue search page. When I type in Senate House Library I want to see the catalogue, I don't want to see things about how old the library is or pretty pictures of the architecture."

I ask about which other library catalogues the participant uses. She uses Copac, the British Library catalogue and WorldCat. She tells me "Copac is definitely the best, definitely, by a mile. British Library is now disastrous, particularly for me who does a lot of manuscript work. [...] But Copac is brilliant. It's simple, it's uncluttered, it finds exactly what you want. [...] It's never failed me. [...] The search terms it offers me are the ones I want. It offers me publisher, it offers me an easy way of doing the to and from dates. I like the way that it shows me what other libraries have got and then I can go straight to their catalogues from it. It's just a very simple way. It's just very simple. But very effective. [...] It's probably the same in the back end, but I think the front end is nice. I quite like having the quickie search at the top, which is often all I need. But there's also the facility to do the advanced search and I think the advanced search has got a lot more than the Senate House one has, ever 
such a lot more." She finds the search options in WorldCat insufficient for her needs, but that's what she uses when she is looking for "American stuff".

I ask if there is anything about the Senate House Library catalogue that she finds confusing and she tells me there is not, but then says "There was one thing in my search where I clicked on something that looked like it had a number and then a subject and then I clicked on it and I got a dead end and I don't know what that is. [...] It was a bit weird and I was quite disconcerted, cos I had to go back and I thought, you know, this should be sending me somewhere correct, but it, it looked useful but it wasn't. " Generally the participant finds the subjects useful. She finds it odd and annoying that sometimes there's a subject that is attached to only one book. "I think half way through the search where I'd been using leisure I suddenly got a hint to use recreation, which I hadn't thought about and I would never have thought about that as a keyword to search for. So that was quite useful, yeah I do find the subject headings useful."

She tells me that she finds "the strings of the class numbers" confusing and that sometimes it's not clear whether the location of an item is one that she has access to. "I don't know whether when I log in and give my ID it's obvious to the catalogue what I can borrow and what I can't. So, for instance, it might say "Heythrop something" and I think, "Well can I have that or not?" [...] It would be quite useful to know is this something it's worth pursuing, cos I can have access to that or not."

"It seems to me that the catalogue here is perhaps trying to make itself more undergraduate than postgraduate, which was my feeling when we went to the change in the last 18 months." I ask if there is anything particular that makes her think this and she tells me "Because it's just these, the quick search I suppose which I did default to. I know cos I've got undergraduate children, so I know how they search and they often are searching for things because their tutor has told them to get it so they're rarely doing subject searches. So the 
emphasis is on you know the author and you know the title. I feel this catalogue has gone back to that as a default, rather than allowing quite complex subject searches, which is what at postgraduate level you tend to be doing more. You're not, certainly at doctorate level, you often don't know if a thing exists or a book exists. Whereas perhaps at an undergraduate level you're directed by your staff to a particular item. So I don't think it's very good for subject searching, personally."

\subsubsection{Participant G}

Wednesday $5^{\text {th }}$ June 2013

Recruitment method: Approached as initiating search in catalogue hall

\section{Observation}

Time: Afternoon

Location: Catalogue Hall

Device: Catalogue Terminal

Search duration: 12 minutes

Just after the participant has signed the information and consent form she tells me that she is searching now to fill up some time while she waits for books she has ordered. The catalogue terminal screen is showing the desktop. The participant double clicks on the catalogue icon and then the Begin your search link which takes her to the quick search screen. She types comics in the quick search box. When the results load she moves the cursor down over the facets and scrolls down the page. When she gets to the Publish date facet she clicks on more $>$ and scrolls down the list of dates that appear. She closes the pop up with the list of publish dates and scrolls back up to the top of the results page.

She adds american to the start of her search so that it reads american comics. When the results load she scrolls down the page, looking at the results. She clicks on the + Items link for one of the records. This shows the location, classmark and status (e.g. 
available) of the item. She right clicks on the title of the item and opens the link in a new tab. She goes to this new tab which shows the full record for this item. She scrolls down the page and then closes the tab.

She continues to scroll down the page of results. She clicks the + Items link for one of the records and, again, opens the full record in a new tab. She goes to this tab and scrolls down to the bottom of the page, then back up and closes the window.

She clicks the + Items link for one of the records and opens the full record in a new tab. She looks at this record for several seconds. This record has a long contents note. She scrolls down to the bottom of the page and back up slowly. She closes the tab.

She amends her search terms in the main search box at the top of the page so that they read american comic books. She scrolls down the page of results this search retrieves, occasionally pausing for a few seconds. She clicks on $\mathbf{2}$ at the bottom of the page to go to the next page of results. She slowly scrolls down until she reaches the end of the results.

She types superheroes into the main search box and runs the search. She scrolls down the page of results and then back up when she reaches the end of the results list. She right clicks on the title of a book and opens the full record for it in a new tab. She opens this tab and scrolls down and then back up the page. She pauses for a couple of seconds and then closes the tab. She scrolls down through the results list again.

She changes her search terms to american censorship and runs the search. She scrolls slowly down the first page of results, often pausing for a few seconds. When she reaches the bottom of the page she clicks on $\mathbf{2}$ to go to the next page of results. She starts scrolling down this page. She opens the record for an item in a new tab, goes to the new tab and scrolls down and then back up the page. Either forgetting or ignoring my request before she started searching to try to ignore me, she turns to me and tells me that one of the 
problems with the catalogue is that it doesn't always say what the book is about. I nod to acknowledge her statement, but don't say anything and look at my notes in an attempt to remind her of my request. She continues to say that it doesn't give her enough information to know whether she wants the book, it doesn't give her a summary like Amazon does. She looks at me as though expecting me to respond. I ask her to try to ignore me for now and to continue searching as she normally would.

She closes the tab for the full record that is open and continues to scroll down the list of results. She scrolls up to the top of the page and changes the word american to self in the search box, so that her search is now for self censorship. She scrolls down the page of results for this search fairly quickly, and then back up more slowly. She changes the search to regulation. She scrolls down the results for this search and then back up the page fairly quickly. She changes the search to regulation books. She scrolls down the list of results for this search more slowly, occasionally pausing. When she gets to the bottom of the page she clicks on $\mathbf{2}$ to go to the second page of results. She scrolls down this page, stops at an item and opens the full record for it in a new tab. She opens this tab, scrolls down the page and then closes the tab. She continues scrolling down the page of results. When she gets to the bottom of the page she clicks on $\mathbf{3}$ to go to the next page of results. This is the last page of results and she quickly scrolls to the bottom of the list of results.

She scrolls up to the top of the page and changes her search to self regulation. She scrolls down the page of results this search brings up and clicks on $\mathbf{2}$ when she reaches the bottom of the page. She scrolls more slowly through the second page of results, occasionally pausing. When she gets to the bottom of this page she clicks on $\mathbf{3}$ to go to the next page of results. She scrolls part way down this page, then quickly scrolls back up and announces she has finished searching. This was not the final page of results for this search. 


\section{Interview}

The participant tells me that she was looking for items on a particular subject. She also uses the catalogue to search for particular items which she knows exist, but more often is searching for "general keywords". She did not find what she wanted in this search. She was looking for any type of item that had information on the subject and she didn't find anything that hadn't already seen. She has previously searched for information on the same subject before, but using different keywords. When choosing keywords to search for she uses the broadest term she can find and uses her knowledge of the subject to think of keywords.

She always uses the main search box when searching the catalogue. She has noticed the advanced search link but has never used it.

I say that at the start of her search I noticed her looking at the Publish dates and ask what she was looking for. She tells me that "something published in the 50s or 60s would have been useful". I ask if she ever uses any of the other options in the left-hand sidebar and she replies "not really", but then goes on to tell me that the tags are useful and she sometimes uses them. She is not sure if the Place facet is where an item was published or its subject.

She tells me "I think the link for floors is always broken". She clicks on the location link in one of the short records that is on screen and this link works. She says "Ok, well now it's not. But at least when I'm at home."

I ask what information in the full record is most useful and she tells me "I usually try to find the summary of the contents". I ask her to clarify and she tells me that she will use either the table of contents or a summary, but "summaries are better obviously, but table of contents will at least give me an idea of what it's about too". I ask if the information is not in the record whether she will try to find out about the contents of the book in any other way and she tells me "usually l'll just Google it". 
I ask if there is anything about the catalogue she finds confusing and she replies "Not really". I ask if there is any way she thinks the catalogue could be improved and she replies "It works for me".

I ask if there was any particular reason she opens a new tab when she looks at a full record and she tells me it is just because she doesn't like using the back button.

I say that I noticed at one point she scrolled down a page of results and then she went back to the top of the page and scrolled down again. I ask if she remembers why she was doing this. She says "I think I was probably just looking at whether there was anything useful on the side."

\subsubsection{Participant $\mathrm{H}$}

Thursday $6^{\text {th }}$ June 2013

Recruitment method: Approached as initiating search in catalogue hall

\section{Observation}

Time: Morning

Location: Catalogue Hall

Device: Catalogue Terminal

Search duration: 15 minutes

Participant takes a notebook and folder containing printed articles out of her bag. Another reader's search is showing on the screen. She minimises this window, clicks on Start on the desktop, then All programmes, looks around the screen for a few seconds and then double clicks on the Google Chrome icon. She writes something in her notebook. Google Chrome has not yet loaded and she double clicks on the icon again. This brings up a welcome to Google Chrome page with a large box asking for user name and password. She closes this window and double clicks on the catalogue icon, clicks on Begin your search, types viktor 
frank $\mathrm{l}$ in the quick search box and runs the search. She says "hmm", takes a printed article out of the folder and spends several seconds looking at it. She turns to me and asks "You don't want me to explain what I'm doing at all?" and I reply, saying no, I just want her to try and ignore me. She scrolls down the list of results and then closes the window, returning to the desktop.

She double clicks on the Google Chrome icon again. She gets up and walks over to the enquiries desk. She tells the member of staff there that Google is asking for a username and password, and asks if she has to log in to use it. The member of staff tells her that logging in is not necessary and walks back over to the catalogue terminal the participant is using with the participant. She tells the participant that she can log in if she has a Google account, and then points at the address bar and search box at the top of the screen and tells the participant she can just use these normally. The participant says, "Ah, I thought it was a special library system". The participant types www.google.com into the address bar and the member of staff goes back to the enquiries desk. The participant types viktor frank 1 au into the Google search box and then selects viktor frankl auschwitz from the autocomplete list that appears. She says "oh" and clicks on the Google result for the Amazon page for a book by Viktor Frankl. She looks at the screen and then writes down the title of the book in her notebook. She scrolls down the page and then clicks on the browser back button. She clicks on the Google result for the Wikipedia article for Viktor Frankl. She scrolls down the page, mutters something inaudible and then appears to be reading part of the article. She writes page numbers down next to the title she got from Amazon - these page numbers are the page numbers given for a quote in the Wikipedia article. She minimises the window that is currently open and double clicks on the catalogue icon on the desktop. 
She clicks on Begin your search and searches for mans search for meaning in the quick search box. She says "Oh, excellent", pauses and then sighs. She moves the cursor so that it is over the record for a book titled 'Man's search for ultimate meaning'. She writes down the location and classmark of this book in her notebook. She clicks on the title for the next book in the list, scrolls down the full record for this item and then back up.

She picks up the printed article and looks at it for a few seconds. She changes her search in the main search box to viktor frankl, runs the search and then scrolls slowly down through the results. She scrolls quickly back up the page when she reaches the bottom, but stops before she reaches the top of the page. She points at the screen and runs her finger along a title, as though reading it. She continues to scroll up the screen. She writes something in her notebook, looking between the screen and the notebook.

She types gillian tillion into the search box and runs the search. This retrieves no results, but suggests another search that the user may have meant. She maximises the Google search window that she minimised earlier. This shows the Wikipedia article. She clicks on the back button to return to the Google search results. She types Gillian Tillion into the Google search box. When the results list loads she says "ah", and minimises the window. The catalogue search window is now visible again. She types germaine tillion into the search box. This search retrieves 2 results and she clicks the browser back button almost as soon as they load.

She changes the search terms to food anthropology and then slowly scrolls down the page of results this retrieves. She scrolls back up the page a little way, and then back down and sighs. She pauses for a moment and then scrolls up to the top of the page. She clicks on the title of the first result in the list, opening the full record for the item. She scrolls down the page, looks at it for a few seconds then writes something in her notebook and says "oh". 
She clicks on the browser back button and then clicks on the title of the second item in the results list. She clicks on the back button, returning to the results list, almost immediately. She scrolls down the list and clicks on another title. She scrolls down the page of the full record and then back up and sighs. She writes something down in her notebook.

She clicks on the browser back button and scrolls slowly down to the bottom of the list again. She scrolls back up to the top of the page, deletes the word anthropology from her search and searches for the term food. She clicks on the title of the first result in the list and scrolls down the page when the full record loads.

She scrolls back up and searches for eatingtanthropology in the main search box. This retrieves no results. She changes her search to eating. She scrolls quite quickly down the list of results this retrieves, then back up the page. She types memory and food into the main search box and runs the search. She scrolls a little way down the list of results, then closes the catalogue window and announces that she is finished.

\section{Interview}

I ask the participant if that search was normal of the sort of search she would do on this catalogue. She tells me that it was fairly normal. She was looking for things for two different projects, so in that sense it perhaps wasn't normal. "I suppose that the first little search was for a specific project where I know I'm looking for specific books, whereas the second one is a project I'm right at the beginning at so was just scoping out to see [...] if it's going to be easy to find books." I ask her to clarify if she is trying to find out what Senate House Library has on the topic or, more generally, what has been written on the topic. She tells me she is "scoping out a field of what people are saying about it. Is there lots of books out there? I don't actually know if it's a field. It's also a play I'm doing [...] with a group of students, so I'm not researching it as academically, I want quite light books, if you know what I mean." 
I ask if she found what she wanted in the first part of her search and she replies "Well, I think so." A passage from a book is quoted in the article she was looking at and she is trying to find the book. The article does not have the bibliography with it, so she only knew the authors name and she knew that it is a "key book" by this writer. She says she thinks she has found the right book but it's a reference book (i.e. not available for loan) and she was hoping to take it out. She tells me that she has also found another book which is about the book she was looking for that she will also look at.

I say that I noticed she searched on Google and ask her to tell me about that. She tells me that when she put the authors name into the catalogue several books came up, so she was searching for the title of the book she was looking for. She was trying to "find the bit where he talked about survival in Auschwitz".

I ask if her second search, the subject search, was successful. She tells me "Not really [...] I suppose I was hoping to discover a whole load of books about food anthropology [...] So this was much more I don't know anything about it at all. So I'm going to do a play about, sort of, minimalism, food and home and I was just starting to think, while I was here, maybe that there's a couple of books I could just flick through, so I would know is there like loads of books out there that I could direct students to. But there wasn't, it wasn't obvious. I didn't really know what I was searching under so that kind of made it difficult. I could have gone on to [...] Google and just done more searching, that's probably what l'll have to do in time. But I just wondered I might try and look at one of these books. Well, this book's [pointing at an item on the list she wrote in her notebook] out so I can't, that's the closest one. But I might look at this book [pointing at another book on the list] and see, sometimes there's references to other kinds of books." I clarify with the participant that this is the first time she has searched anywhere for information on this topic. 
I ask if she ever uses the catalogue in any other way than the two she has just spoken about. She tells me that at home she mainly uses it for journals, both to find known articles and to find articles on a subject. "I find the new design of the Senate House catalogue really, really difficult to access. [...] They've hidden the journals page. You used to be able to get access to all their different electronic databases of journals. [...] It's really difficult to find now." She tells me that this is when searching for known databases. Her favourite database is JSTOR, which she has been able to find using the new interface. There a couple of others she used to use, but hasn't been able to find using the new interface, although "I haven't looked properly. I've been feeling a bit despondent."

I ask whether she always searches the catalogue using the main search box and she tells me "I do sometimes do the advanced search if I'm looking for something specific." I ask her to clarify and she tells me that if she wanted only to search in books or only in journals she would use it and that "I use the advanced search on the journal search engines most. [...] Do I use it on the Senate House catalogue? [...] I don't think I use it that much because quite often even if you get the title wrong it does come up. [...] I suppose I would use it if I just knew the author." She would always try using the main search box first.

I ask if she is aware of the options in the left-hand sidebar of the results list screen. She says she is not, then brings up the search screen on the computer to look at it and says no, she hadn't noticed it before. Pointing at the refine by facets, I ask her if it is obvious to her what they are for and she replies "no". I explain what they do and she says "Oh, I see, so it's like advanced search, but down the side." I ask if this is something she thinks she might find useful and she says "yeah, I would think so". I point out the Refine by tag and Related search boxes and she says "I think that's interesting. I suppose generally for me I'm looking up specific books, but actually for the second search that would have been useful, cos I don't know the area at all." 
I ask if there are any other features of the catalogue she finds useful or a hindrance. She tells me "I do find the catalogue quite annoying. One of the main things is this kind of thing [pointing to the location in a short record], so you get really excited cos the book's there and then you've no way of ever accessing it cos if it says something like that." I confirm with the participant that the location is a library she does not have access to. She continues, "sometimes when you've been looking for a long time you think it's there and then you can't find it."

"I suppose I find the catalogue fairly bog standard. I don't probably use it that much other than just to check if the book's there. I spend most of my time on the journal search engines."

I ask what information in the full record she finds most useful. She tells me that one of the books she found during her search was an autobiography and she looked at the full record to try to find out whether the content included the part of the authors' life she is interested in. She says she also goes into the full record for the [publication] date, she then notices on the screen that the publication date is included in the short record and says "oh, I suppose it's got it here, the date of publication. My one at Central doesn't, so I usually go in to find the date of publication." When I ask she clarifies that by Central she means the library catalogue at the Central School of Speech and Drama. I say that full records include subjects and sometimes a summary or table of contents. She tells me she does sometimes use these and finds them useful.

I ask why she started her search in the catalogue, but then almost immediately went to Google. She tells me "I put Viktor Frankl in because that's the only reference I've got in this article and [...] all these books came up and I wasn't sure which one, what his big idea was basically. I wanted to find the book where he talks about this issue survival, reason to survive." 
I say that I noticed she Googled another name after the Viktor Frankl search and ask her to tell me about that. She tells me that this was for a search for another book by the author Germaine Tillion which she wants for a chapter she is writing. She wanted to check whether the library had what she is looking for while she was in the library. The book is in French and she is having trouble getting hold of it. She tells me that the library didn't have it.

I say that at one point I noticed she was scrolling right down to the bottom of a record and appeared to be looking for something. I ask if she was expecting to find something else. She replies "No, I think I was just trying to work out, I was quite interested who this guy was and I think I was just [...] cos I don't know anything about him and I was trying to work out who he was I suppose because it's in psychology so I don't actually know anything about him. [...] I was kind of working out who he was and whether he wrote a philosophy book or a psychiatry book cos I didn't know that and it was in psychology, I thought it might be in philosophy."

I say that I noticed in one of her searches she used a plus sign between two terms and ask why she did that. She says "I'm not very good at searching. ... I just thought it might, I dunno. [...] This was part of my next project which I haven't done any work on. But I think I was just trying to see if there was any, another way of looking that might open up more possibilities. ... Some catalogues do more keywords and sometimes this one ... I find it a bit more stubborn the one at Central. My one at Central if you put any word in it just sort of brings up anything vaguely related to it and I don't think this one does it quite as easily. So I just thought l'd try it."

I ask if there is any way the participant thinks the catalogue could be improved. She tells me "Well, I'm dyslexic, I find the whole of these places really very stressful and difficult to get. I find it's probably the labelling. I find them really hard. And then there's, I'm never sure what information I have to write down here when I go look for the book. So I'm pretty sure I have 
to put the sixth floor and that 67 thing as well. I find that really difficult to translate it back into then looking upstairs for the book. My main complaint though is the journal issue that on the homepage you can't find it easily. [...] and it's really difficult to renew your books cos it's in a very little box right at the bottom. And then this whole page has got loads of other guff about stuff I have no idea what it's about."

\subsubsection{Participant I}

Thursday $6^{\text {th }}$ June 2013

Recruitment method: Historic collections survey

\section{Observation}

Time: Afternoon

Location: Sterling Library Reading Room

Device: Own - Windows Notebook

Search duration: 10 minutes

The participant opens the main search page in Google Chrome. She types manuscripts in walters art gallery into the search box and runs the search. She scrolls down the results list. She clicks on + Items in a short record which brings up the list of items for that record and their locations, classmarks and whether they are available. She opens a MS Word document which is minimised and types something in it (it is too small for me to read). She goes back to the catalogue window and scrolls down the page, and then back up.

She clicks on advanced search and conducts a search for Author scott and Title later gothic, leaving the Boolean connector as AND. This search returns two results. She opens the Word document and types something in it. She moves back and forth between the Word document and catalogue windows, typing more. 
When in the catalogue window she clicks on the browser back button which takes her to the advanced search screen. She conducts a search for Author MORGAN AND Title manuscripts. She scrolls down the list of results this search retrieves. She clicks on the + Items in two short records and then continues scrolling down. She opens the Word document and types something, then returns to the catalogue window and continues scrolling down the page. She clicks on the + Items for a record and then goes back the Word document and types in it. She goes back to the catalogue window and scrolls down the results list. When she reaches the bottom of the page she clicks on $\mathbf{2}$ to go to the next page of results.

She opens the Word document window and types something. She moves between the two windows several times, typing in the Word document. She goes back to the catalogue and scrolls down the list of results. When she reaches the bottom of the page she clicks on $\mathbf{3}$ to go to the next page of results. She scrolls part of the way down this page. She opens the Word document again and spends several seconds looking at it. She gets up and walks to the palaeography room. She scans the shelves, takes two volumes down and then tells me she is finished.

\section{Interview}

I ask the participant if that search was normal for the sort of search she would usually do on the catalogue. She tells me "Yes, although usually I would look up before I get to the library. Today I forgot my piece of paper that had my long list of everything I've been looking at, you know, for the past three years so I had to kind of just do it on the fly today." I ask if she looks items up one at a time or a long list of things all at once. She tells me "I usually look up a bunch of everything I think I'm going to need that day. And then especially with the palaeography collection it's a lot of just go and see what's on the shelf around the books that I'm looking for because it's all very similar and so I end up finding a lot more things that 
I didn't realise were there just by going to that section." I ask if those are things that she had found on the catalogue and didn't think would be useful or things that she hadn't found at all and she replies "both".

Her search today was for known items. The second item she wasn't sure whether it was at Senate House Library or the Warburg Library. "The first ones were books. I had been looking for a manuscript catalogue of manuscripts at the Walters Art Gallery but I couldn't find it just by searching in the online catalogue because I kept using the words catalogue and manuscripts, but the actual title of the book doesn't have the word catalogue in it so that was why I couldn't find it, but I just happened to find what I was looking for on the reshelving shelf and so I type in - there was just two volumes there and I wanted the other volume so just going off of what I found on that shelf I was able to figure out what the real title was and type that into the search engine." I ask whether she found everything she was looking for in her search and she tells me she did.

I ask if she ever uses the catalogue to search for items on a subject, rather than for particular items she already knows of. She tells me "I use it a lot to access JSTOR, but not for just random topic searches."

I say I notice she started her search in the main search box and ask if she ever searches the catalogue in any other way. She tells me "Not usually, unless I know exactly the author and more specifically the title, but usually just the main browse search does it."

I ask if she has noticed the left-hand sidebar on the results page when she searches the catalogue and she replies "I guess not". I describe what it contains and she confirms that she has not noticed it. I ask if she thinks the refine by options would be useful to her and says "Yes, like today I got four pages of results and I figured out by page three that the results were getting too old for my interests, but if I'd just been able to filter that out earlier 
that would have been better." I ask if she thinks the tags would be useful to her and she replies “I don't know, I mean pretty much everything I look for is under the same kind of subject heading so I don't know how helpful that would be for me."

I ask why the participant started using the advanced search part way through her search. “Because I was looking for a book and I didn't know exactly the title by an author that's written quite a lot so I thought that might help narrow it down just a bit cos he's written a lot about manuscripts and I was looking for a book that has manuscripts in the title so I thought narrowing it down might help get a smaller search."

The information in the full record which the participant finds most useful are the title and the date - "the title's usually specific enough that I can figure out it's what I'm looking for." I ask if there is anything about the catalogue that the participant finds confusing or any way she thinks it could be improved and she tells me "Sometimes I'm confused about the stack search items whether once they are delivered if they're reference only or if I can actually check them out. I think that's a little unclear sometimes. And, as I say, I use it a lot to get to JSTOR and it's quite a kind of convoluted process having to log in and go back to the catalogue and then go to the e-databases and then sign in and put your password in again to get to JSTOR. It's a lot of steps to get to it so if that could be minimised that would be easier. [...] Oh and I had a problem with stack search a couple of times when I logged in to see if the item had been fetched it said that it had, but I didn't get the email telling me that until the day later by which point it was too late because I had been expecting it to get there that day."

I ask if she had any particular reason for typing in an author's name in capitals in one of her searches. She tells me she just had caps lock on by accident. 


\subsubsection{Participant K}

Friday $7^{\text {th }}$ June 2013

Recruitment method: Approached as initiating search in catalogue hall

\section{Observation}

Time: Afternoon

Location: Catalogue Hall

Device: Catalogue terminal

Search duration: 1 minute

Participant conducts a Google search for logic is formal and opens a pdf from the search results. He quickly scrolls through the pdf and then highlights the editors of a book in the references - Kanger and Ohman - which he copies. He opens a new tab and clicks on the link to the catalogue in the favourites toolbar. This brings up the catalogue showing a previous search. He pastes Kanger and Ohman into the main search box and runs the search. This retrieves one result. He gets up, rushes over to the other catalogue terminals where he takes a piece of paper from the scrap paper box. He comes back, writes the classmark of the book the search retrieved on the piece of paper and tells me "I've found it".

\section{Interview}

I ask the participant if that search was typical of the type of search he would usually do on the catalogue and he replies that it was. He confirms that he was searching for a known item. At the start of the search he used Google to find a reference for the item he was looking for. I ask why he chose to copy the words from the reference that he did and he tells me "I tried it yesterday and it worked, but it would be standard practice anyway. Cos I've found if you look up the editors of a book generally you can find it. [...] It's useful."

I ask if he uses the catalogue for any other purpose and he tells me "If I'm interested in a particular author, I'll type the author in, if I'm interested in a particular topic then I'll type 
the topic in. [...] I suppose if you have a specific book in mind and you know the editors or the author and you type the author and the name of the book it's very good. If you type a general thing, like quantifiers, then it can be quite, let's say, the luck of the draw. [...] And sometimes it comes up with items that are not in the Senate House Library and are just in the University of London, like the classics library. Which is all very well and good, it means I can go there but I can't necessarily get them out and sometimes I don't notice at first that it's from the classics library." I ask if he knows how to refine his search so that it only shows items from Senate House Library. He replies "vaguely, but I've never properly [...] I mean when I use the advanced [clicks on the advanced search link], no I don't really use the advanced." I point out the facets in the left-hand sidebar and ask if he has noticed them before. He has, but has not used them and has never found it necessary to use them. I point out the location facet and ask if he was aware he could use it to refine the location to just Senate House Library. He says "Ah, yeah and I have sort of noticed that at the time and then I forget how to do it so it's all very spontaneous. [...] Because l've got membership of multiple libraries, so I've probably got membership or access to the other ones." I ask if he finds it useful to be able to search multiple libraries on the same catalogue and he replies that he finds it "fairly useful", but that he thinks for most people it would be more useful to just search Senate House Library. "It depends whether you're an undergrad as well because I don't know that all undergrads will want to go and look it up in random library $\mathrm{X}$ whereas I, cos I have a Sconul card so I can just go and see and get access."

I point out the Refine by tag section and the participant tells me he has never noticed it, but thinks it would be useful to him. "I'm sure there are many things that would be useful, but I just don't always have the time or the patience [...] I'm not a computer person in general so I'm not the kind of person who would click on things randomly and experiment. I just plump for the search usually and put the name of the book in." 
I ask if he ever searches using the classic catalogue. He is not aware of its existence. When I show it to him he recognises it and says he has stumbled across it before, but not used it. He goes on to say "I'd prefer that it was automatic that it came there [indicating the classic catalogue now on the screen]. But again, I contradict myself, cos I've said on the one hand that I don't care cos I have access to all the other libraries, but then that depends on my mood and if it's a book that's really important to me and that I'll want to look at [...] then I'd prefer a general search." I ask him to clarify what he means by a general search and he tells me "a search that shows up the classics library and all of the others. If I just feel, oh I'm interested in quantifiers or something, then I don't really care about going to Kings College or somewhere and I just want to work here this afternoon." He tells me he would like to have the option to choose whether to search in just Senate House or everywhere. Also, he doesn't find the catalogue is clear about where is being searched. He suggests including a drop down list on the main search screen to choose where to search.

He goes on to say "But I think it's quite a good search system it's better than some of the other ones I've found. [...] like the Kings College one, I think the Birkbeck one is slightly better, I think the UCL one's ok. I think this is quite a good one." I ask if there is anything particular about the catalogue that makes it good and he replies "I suppose it's more my familiarity with it and that it just seems clearer [...] Why does it seem clearer? Because, hmmm [...] it just seems clearer to me."

I ask if there are any other features of the catalogue he uses. He tells me "One thing that's really wonderful is the fact that you can access the internet whilst searching. I mean, I think there are some libraries where it's not so easy." He confirms that he means that he is able to use the internet on the catalogue terminals. He doesn't always remember the title of specific books that he needs or carry the reference with him, but knows where he can find the reference on the internet and can then copy and paste his search terms into the 
catalogue. He always uses Google to search for where he knows he can find the references he needs.

I ask what information in the full record is most useful to him when he is searching for books on a topic. He tells me that mostly he uses the author. In subjects that he is familiar with he uses his knowledge of authors' reputations, while in unfamiliar subjects he will search for the author using Google. He goes on to say "I think the content of the book is really the most important thing, it's just that I've got limited time so I have to have an idea that the person has been written about [...] But then that depends again." He says that generally he finds books are more or less clustered together, although not always. Sometimes books are not in the location he thinks they should be, for example he found that books on the sociopolitical aspects of AIDS were in the American section. "I found loads of clusters of books and if I hadn't heard of the author I just thumbed through the book and had a cursory idea, maybe looked in the index and thought are there some things of interest to me here." $\mathrm{He}$ has also noticed books on linguistics in the English section which he felt should be in the linguistics section, "which maybe should be either put in the linguistics section or sort of flagged up on the search screen as somehow indicated that they're $[. . .]^{\prime \prime}$. I ask if he ever looks at the subjects in item records on the catalogue. He replies "Not really, I never no. It might be more useful. Maybe it would just make the same result, I don't know. [...] But the thing is these categories are sometimes a bit vague anyway so the stuff that people about in philosophy can be very similar to the stuff in linguistics."

I ask if there if anything about the catalogue the participant thinks is confusing and he tells me that there isn't. Indicating the full record on the screen, he tells me that he doesn't know what a community tag is and wouldn't use it and he has an ancient phone so wouldn't use the QR code, but they don't confuse him. 


\subsubsection{Participant L}

Friday $7^{\text {th }}$ June 2013

Recruitment method: Approached as initiating search in catalogue hall

\section{Observation}

Time: Evening

Location: Catalogue Hall

Device: Catalogue terminal

Search duration: 6 minutes

The participant double clicks on the catalogue icon, which opens the quick search screen. He selects Title from the drop down menu to the left of the search box, types self help in the search box and runs the search. The results are returned with the classic catalogue interface. He clicks on the first title which brings up a list of three results with that title. He clicks on the browser back button and then clicks on the second title in the results list. This brings up the record for an item. He clicks on MARC display, looks at the record for a few seconds and then clicks on the browser back button twice to return to the list of results. He clicks on another title in the results list, which brings up the record for an item. He moves the cursor over the subject headings and appears to be looking at them for a few seconds. He clicks on the browser back button and scrolls slowly down the list of results. He scrolls back up and clicks on the first title in the results list again. He clicks the title for one the results displayed in the list and, when the full record for the item appears, clicks on MARC display. He looks around the screen quickly and then clicks the browser back button twice to return to the main list of results. He looks at the page for several seconds and then amends the terms in the search box to self development, leaving the drop down as Title. He runs the search and clicks on the first title in the results list. He clicks the browser back button twice, returning to his search for self help, changes the search to 
KEYWORD and runs the search. He clicks on the title of the first item in the results list, looks at the full record for a few seconds, then clicks the browser back button and turns to me. I ask if he has finished searching and he says he has.

\section{Interview}

I ask the participant whether the search was typical of the sort of search he usually does on this catalogue. He tells me that usually he uses the catalogue find books that he already knows exist and, usually, that he knows the title and author of. In this search he was using the catalogue because there is a field he wants to know more about.

I ask if the participant found what he wanted in his search. He tells me that he didn't and “I think that's because I don't know the terms to search, so that's why I'm going to talk to the reference person and just kind of throw out some ideas and he or she will help me, you know, kind of boil it down."

I ask why he chose to start by searching by title and he responds "Because I hate the keyword search cos it's too vague and it brings back like thousands and thousands. And so often whenever I'm searching for a theme if I go into like a title or a keyword title search, it helps me really, like, focus the search and sometimes, like, more often than not, I actually find something that's exactly what I wanna look into. And then I find that record and then I go to the subject headings to find all the other available works that are about that."

I ask if the participant is aware that there are two different interfaces for the catalogue and he tells me that he is not. I show him the main search screen to confirm that he hasn't used it before and he tells me he hasn't. He tells me that at home he uses the search box on the Senate House Library website homepage. I inform him that this would take him to the new catalogue interface and he says "Oh, ok". I ask if he is aware of ever having used the advanced search in the new catalogue and show him the advanced search screen. He replies "Sometimes, because I really hate keyword searching and I feel like a lot of the catalogues 
and a lot of the databases are just dumbing down, dumbing down, dumbing down." This really irritates him and he particularly dislikes JSTORs current search options. He much prefers how catalogues used to be "years ago" and thinks that it was much easier to focus a search with them, for example by searching for words adjacent to one another.

I ask if he refines his searching in anyway. He tells me that he uses dates and "usually I try to kind of find something as focussed as possible and then go out as opposed to kind of starting with something general and then kind of do it."

I ask what information he finds most useful in the full record when searching for information on a subject. "If they do have a table of contents, that's the most useful thing, especially for edited volumes and you can see why it's this subject heading. [...] So that's probably would be the most useful thing. Usually I just do like keyword, title, then the subject heading and then everything comes up and I can go through them just by the title to see if it's useful." I ask if there is anything about the catalogue he finds confusing. He replies, "Not particularly. I think it's pretty straightforward. [...] Sometimes, I know it's a cataloguing thing, I know that certain books that were catalogued in certain years have a very wonderful catalogue record, they have like lots of subject headings, like four, five, six. And then some don't have any subject headings and I find that really frustrating. But that's not a catalogue thing, that's a data thing."

I say that I noticed he opened a MARC record a few times and ask why he did this. He replies "Because I found out with other libraries sometimes - usually the subject heading is like a 650 field, but it can be 651,652 , some other weird number sometimes or like 700 s and sometimes I've noticed that a lot of different catalogues they don't pull in all that information when they put subject headings. So when I did open the MARC it was because there was no subject headings that were listed on there and I just wanted to check that they 
were feeding in properly." I ask if the field numbers are relevant or mean anything to him. He tells me they are not, he is just looking for any subject headings.

I ask if there is any way he thinks they can be improved. He responds "Well, I don't really know if it's a catalogue thing. It would be great if everything had, like, subject headings. If you were able to kind of click the subject heading and find all the books that were, like, basically under that subject heading, which I imagine you can do." He demonstrates using a record that is on screen, clicking on a subject heading. He tells me he would then sort by date. I ask if he often uses the sort by options. He tells me he does, "usually because I want to find the most recent $[\ldots]$ whatever."

I ask if there is anything else about the catalogue that he thinks might be relevant. He tells me "I [...] think it's good, it hasn't been dumbed down like some have. Like some university catalogues are just useless." I ask if he can't find things with them or if he finds them difficult to use. He responds, "They're just dumbed down so much that everything's, like, a keyword search. [...] And it's kind of like this is a waste of my time, cos I get 2000 results and they only show, like, 10 items per screen and then you have, like, what? 200 to go through and I just hate that. I really think that they kind of think all their users are idiots. [...] Especially in some of the cases they've actually, like, streamlined it, but they've actually dumbed it down. And so their previous catalogues were much more useful to someone who actually knows how to search for things."

I ask if he finds the new advanced search as useful as the classic catalogue he used for his search. He says "Maybe, actually I should go back to the advanced search" and I direct him to the advanced search screen. When he gets there he says "I do like this one, I like the Boolean operators cos it really helps me, like, focus things. I'd forgot about this actually, but yeah I have used this a couple of times, yeah, it's great. I really like it." 


\subsection{Appendix C: Demographic questionnaire results}

\begin{tabular}{|c|c|c|c|c|c|c|c|c|c|c|c|}
\hline 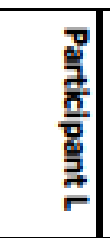 & 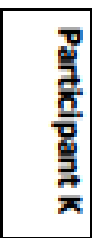 & 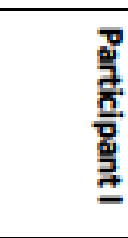 & 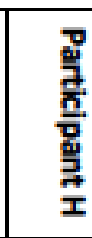 & 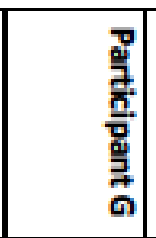 & 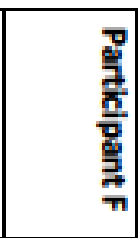 & 惫 & 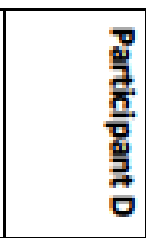 & 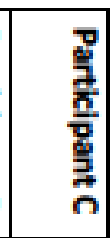 & 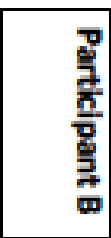 & 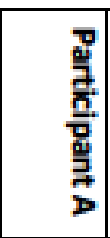 & \\
\hline 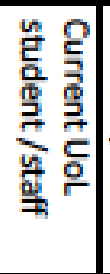 & 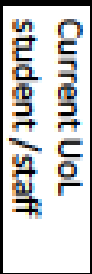 & 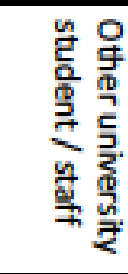 & 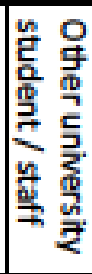 & 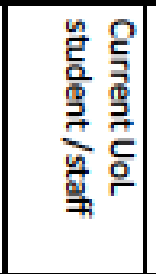 & 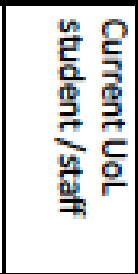 & 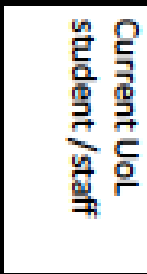 & 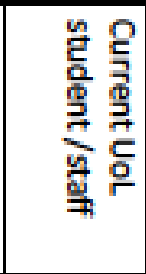 & 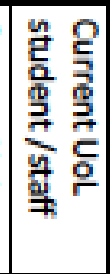 & 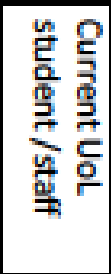 & 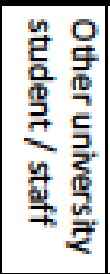 & 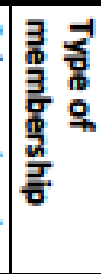 \\
\hline 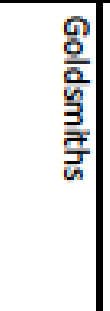 & $\begin{array}{l}\text { 䍗 } \\
\text { 芶 }\end{array}$ & 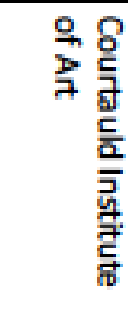 & 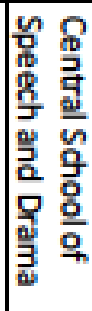 & 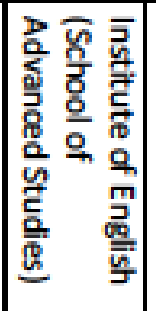 & 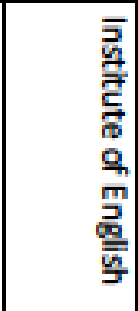 & 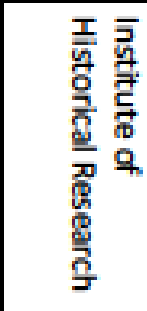 & ऽิ & $\begin{array}{l}\text { 䍗 } \\
\text { क्र } \\
\underline{2}\end{array}$ & ᄃิ & 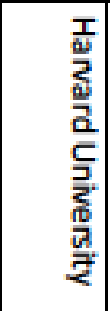 & 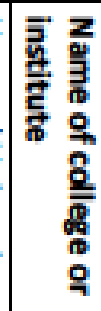 \\
\hline 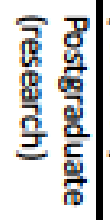 & 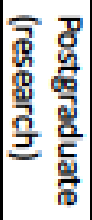 & 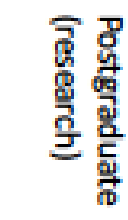 & 望 & 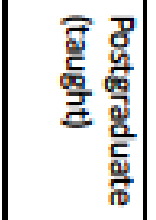 & 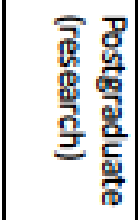 & 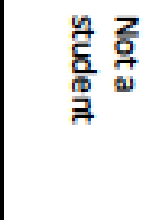 & 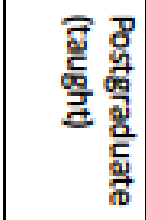 & 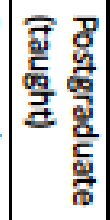 & 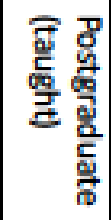 & 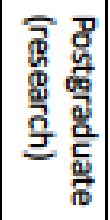 & 敢 \\
\hline 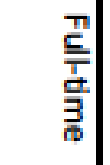 & 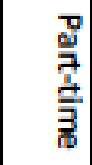 & 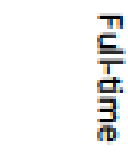 & $\frac{z}{s}$ & 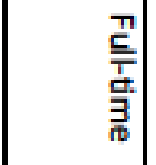 & 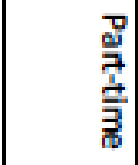 & $\underset{s}{z}$ & 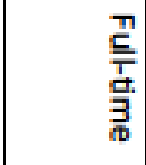 & 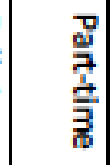 & $\begin{array}{l}\frac{\pi}{5} \\
\stackrel{\tau}{3}\end{array}$ & 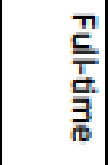 & 些 \\
\hline 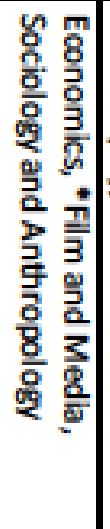 & 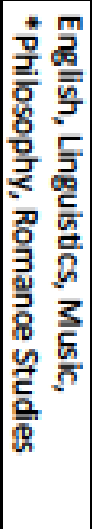 & 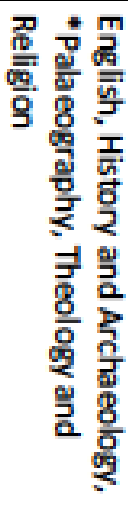 & 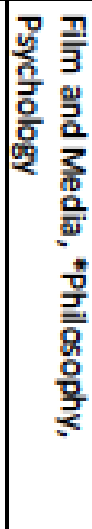 & 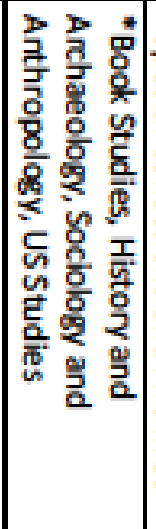 & 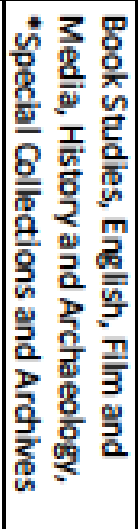 & 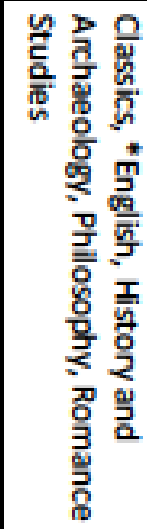 & 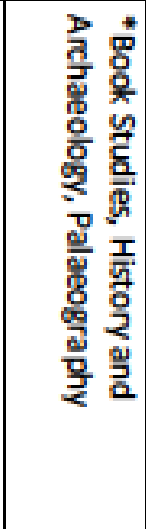 & 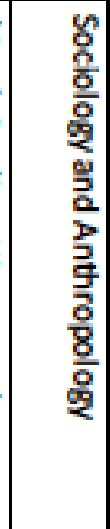 & 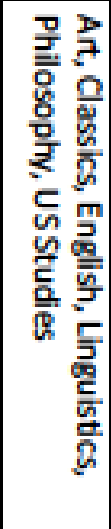 & 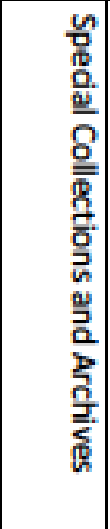 & 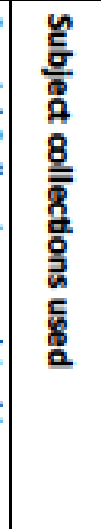 \\
\hline 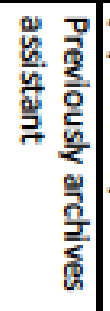 & 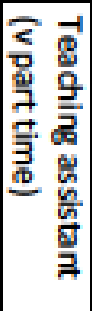 & 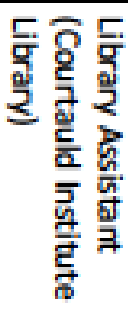 & 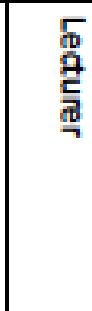 & $z$ & 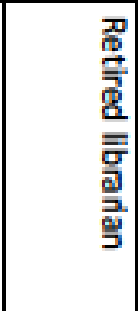 & 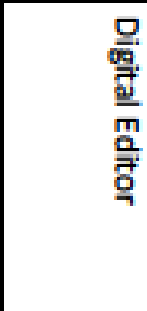 & 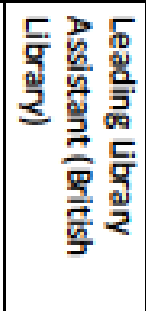 & 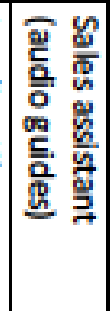 & $\frac{z}{s}$ & $\frac{z}{s}$ & $\begin{array}{l}\text { 을 } \\
\text { 窵 }\end{array}$ \\
\hline$\Psi_{\pi}$ & 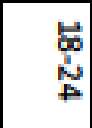 & & $\begin{array}{l}\psi_{\Pi} \\
\$ \\
\$\end{array}$ & & 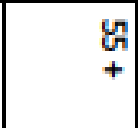 & & & & & 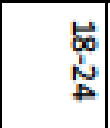 & 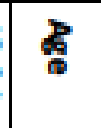 \\
\hline
\end{tabular}




\subsection{Appendix D: Historic collections survey results}

\begin{tabular}{|r|l|l|l|}
\hline Respondent & $\begin{array}{l}\text { Have you searched the } \\
\text { catalogue this week? }\end{array}$ & $\begin{array}{l}\text { If no, do you use } \\
\text { the Senate House } \\
\text { Library catalogue? }\end{array}$ & $\begin{array}{l}\text { How did you know Senate } \\
\text { House Library had material you } \\
\text { wanted? }\end{array}$ \\
\hline 1 & Yes (at home) & N/A & Word of mouth \\
\hline 2 & Yes & N/A & Copac \\
\hline 3 & Yes & N/A & SHL catalogue \\
\hline 4 & Yes & N/A & Copac \\
\hline 5 & Yes & N/A & SHL catalogue \\
\hline 6 & No & Not sure & $\begin{array}{l}\text { From a printed list of archival } \\
\text { material with locations - not } \\
\text { sure where this came from }\end{array}$ \\
\hline 7 & Yes (at home) & N/A & SHL catalogue \\
\hline 8 & Yes & N/A & $\begin{array}{l}\text { Programme introduction } \\
\text { (postgraduate research) }\end{array}$ \\
\hline 9 & Yes & N/A & $\begin{array}{l}\text { Don't yet - about to search SHL } \\
\text { catalogue for it }\end{array}$ \\
\hline & & &
\end{tabular}

\subsection{Appendix E: Research diary}

A research diary was kept during the data collection week of this research to record thoughts on the application of the method and the data being collected. This information was used to improve observation and interviewing technique and to develop the framework for the interviews.

\section{Monday $3^{\text {rd June }}$}

\section{$7.45 p m$}

First day of field work and I have conducted observations and interviews with 2 participants, and written up the field notes. Both were recruited as they sat down at a catalogue terminal in the entrance hall. I also had a meeting this afternoon with Anne to discuss how my first day of data collection had gone.

Taking notes whilst observing the participants was not too difficult and worked well. On the other hand, as was the case in my trial run of the method, I found it very difficult to take good notes while conducting the interview. Listening to what the participant was saying and 
thinking about what I should ask next took up too much mental capacity to leave enough to write good notes. However, recording the interviews worked well and allowed me to write up good field notes on the interview. This does leave me with the potential problem that I am reliant on the recording, so if the recording device does not work or there is any problem with the recording I will find it very hard to make good fieldnotes. So far recordings have been very clear, even when there were several other people having conversations in the catalogue hall, and I have had no problems with the device.

Participant A, although perfectly willing to participate, was rushed in the interview and this meant I forgot to prompt him about what information in the catalogue is most useful and whether there were any other features of the catalogue he used. I also forgot to ask participant B about whether he had been looking for something at the end of his search when he was moving the cursor around the top of the screen. Therefore, with subsequent participants I need to remember to put an asterisk in the margin of my observation notes when there is anything I want to ask about in the interview. In the questionnaire Participant B listed 6 collections that he uses; it would have been useful to ask him which collection he used most - I will do this with future participants who list multiple subject collections.

I found that both participants today gave short answers and needed quite a lot of prompting to expand on their answers. I started each interview with the question "Was that a typical search for you?", which seemed to confuse both participants. In the rest of the interview I avoided yes/no questions and used questions such as "Could you expand on that?" and "Tell me more about that?". Possible explanations for the difficulty in getting participants to speak at length may be: interviewer effect (I or my style of questioning could make people answer briefly); that today's two participants were just the sort of people who give short answers; they are not sure what to say without prompting because they have not thought about the catalogue, it's features and their use of it before and need directing. That they 
were both doing relatively short searches for known items may also have affected how they responded in the interview. I will read up tomorrow morning in the research methods textbooks I have whether there is anything else I could be doing to encourage fuller answers.

After my meeting with Anne I have decided that I also need to observe for and record body language / movements during the interview and include more and longer quotes in the write up of the interview.

One interesting thing I noticed when I was writing up the notes for Participant B was that when questioned about using facets to refine searches he stated that if he searched for an author with a "generic name" or just a surname and the results retrieved included several authors, he would select the author he wanted to refine the results. The Senate House Library catalogue does not have an author facet. I will email Andrew to find out if this a feature that has been removed from the catalogue recently. If it is not, this is interesting because it suggests that the participant may be confusing different systems. He is a UCL student and the UCL Explore library discovery layer does have an author facet, and this is possibly the origin of this comment. Listening back to the recording I was very clear that I was asking questions about the use of the Senate House Library catalogue, and not library catalogues in general, so it is not likely that the question was misunderstood in this way.

Recruitment is still a concern. Both people I approached in the catalogue hall today were willing to take part, and I do not think I will have too much difficulty recruiting catalogue hall searchers, but I have so far only recruited two expected participants via the blog / Twitter (one special collections user and one 'other' user) and one recruit via word of mouth. Approaching people as they walk through the entrance hall to ask them if they will be searching the catalogue anywhere in the library during their visit and asking whether they would be willing to take part in the study is a possible recruitment method. Anne also 
offered at our meeting to email students in the department as another recruitment method if, by midweek, it does not look like I will get enough participants.

\section{Tuesday $4^{\text {th }}$ June}

\subsection{0am}

In later than intended this morning following bike problems and a missed train. After rereading chapters on interviewing in Schensul et al. (1999) and Gorman and Clayton (2005) I have decided to change my initial interview question to "Tell me how similar that search was to how you normally search the catalogue?". Rather than have a list of set questions, I will just have a list of topics I want to cover. It will also hopefully make me sound more conversational. I am also going to introduce the topics of: using the catalogue in any other way or for any other purpose (to what they did in the observed search); did they find what they were looking for? (I can't think of a good way to put this other than as a question); anything about the catalogue that they find confusing; and any way the catalogue could be improved. The last two of these themes in particular will hopefully encourage participants to think about and talk about their experiences with the catalogue (although, admittedly, with a negative slant).

I also need to ensure that I make it clear that my questions are to guide the interview, but that the participant can talk about anything they think is relevant (if they talk about something that isn't relevant I can just ignore that part of the field notes, or stop them if they go on too long). Also, when I want to clarify something the respondent has said, it would probably be better to wait until they have finished answering the question, rather than just asking when they pause.

Thinking further about the difficulty of getting participants to talk at length, perhaps it is the naturalistic setting meaning they don't think in depth about what I ask them - they probably 
don't usually think a lot about how they are using the catalogue and why they are doing what they are doing.

I have also decided that keeping a spreadsheet of participants responses to the questionnaire answers, along with the method by which they were recruited will be useful to help me keep track of the participants (and will also be a useful addition to the appendices of the dissertation). To ensure I know how people were recruited I will ask those who have contacted me via email where they found out about the study (historic collections leaflet, blog post, twitter).

\subsection{0pm}

I've had three participants today. I found it much easier to get them to give longer answers than the participants I had yesterday. I think this was mostly because the three participants I had today were more 'chatty'.

One problem I did have though, was that Participant $D$ was very quick at typing and moving around the catalogue. This made it difficult for me to write notes fast enough to keep up with what she was doing. There was one search she did where I missed the search terms altogether. This makes the data for this participant less complete, but I do not want to decide to exclude it for that reason, because that would be excluding her because of her style of searching and I think I was able to get enough data from the observation. Struggling to make notes fast enough also meant that I found it harder to think about what questions I might want to ask her about the search in the interview. There were several things I noticed when writing up the observation notes that would have been good to ask her about and that I think I would have noticed at the time had she not been going so quickly. There were however some pauses in her searching, for example when she was writing things down. I could have used these to quickly look over the notes I had just made and think about what I 
might want to ask about while, of course, keeping one eye on the participant to continue observing. I will remember this if any of my future participants are 'fast searchers'.

Writing up my field notes is taking longer than I had anticipated. I succeeded in writing up the observation notes for all three participants I observed / interviewed today, but the interview notes for only half the first interview. Writing up the observation notes for Participant $D$ was particularly time consuming due to some difficulties interpreting rushed handwriting and because she had moved about quickly she had done quite a lot for the amount of time she searched for. The observation notes are the most important to get written up as soon as possible after the observation because the observation is not recorded in any other way, and although it is based on what I write down, it is also based largely on memory. Therefore the writing up of some interview notes may have to wait until after I have completed data collection. Since I have recordings of the interviews I do not think this will affect the quality of these notes. I will make sure that I listen to the whole of the recording of each interview as soon as possible after the interview to make sure it is complete and audible. Not writing up all the interviews as I am conducting the fieldwork gives me less information to consider and feedback into future observations / interviews, but given time constraints I think it is better to concentrate on getting enough participants. Listening to the recordings of the interviews to check them will possibly give me some ideas that can feedback into the fieldwork.

\section{Wednesday $5^{\text {th }}$ June}

\subsection{5am}

Thoughts from listening to the recorded interview for Participant D:

- Where do participants get keywords from - here using bibliographic references in another book for ideas

- Use of tags (in left-hand sidebar) - relevant of what these links do? 
- Saved search only kept for duration of search, would like to keep this after log out

- With things that are put at the bottom of page (in this case recent searches) - even though know they are there forget about them because can't see them

Thoughts from listening to the recorded interview for Participant E:

- Use another catalogue to find things first and then do known item search

- To find things on a topic search for something that is an example of that topic and use results to get ideas for search terms

- Use classic catalogue for complex searching because "it is better"

- Can't keep saved searches after log out - problem

- Don't find subjects in record useful - interesting because the second search term he used appears to have come from one of the subjects and he clicked on a subject in a record to get to the list of results which he said was what he wanted

- Preference for physical over electronic items

- Book covers useful

Another thought from having listened to these recordings is that sometimes when I am seeking clarification of something the participant has said I ask leading questions - stating what I think they mean and asking if that's right. To avoid interviewer bias I need to avoid doing this. I could use questions such as "Could you just explain what you mean by x?" or ask them to show me - a couple of participants did this yesterday when I was asking for clarification and it was a good way to get clarification (obviously I can only do this if interviewing them at a computer). Also, asking "Are you aware that x exists?" is not a good question - they will probably want to seem knowledgeable and are possibly more likely to say yes. However, if I have already asked if they know how to do something, and they do not mention what I am looking for, I can't think of any other way of checking if they have 
noticed something (they may have noticed it but not realised what it does or forgotten about it).

\section{$1.55 \mathrm{pm}$}

Thoughts from listening to recorded interview for Participant F:

- Has problem not being able to find known item because of spelling and suggests catalogue should have a "do you mean ...?" feature - does not realise this already exists - then points out that she would like this for titles and authors

- Uses Copac to find items in SHL if can't find them in SHL catalogue - simple and clear, but effective; advanced search has a lot more

- Idea of a right and wrong way of searching (reflects that maybe she searched in the wrong way)

- Problems with finding online databases via subject searching

- $\quad$ Problems with Export to EndNote link

- Tags and subject useful way to search

- "it seems to me that the catalogue here is perhaps trying to make itself more undergraduate than postgraduate" - doesn't allow complex subject searches

\section{Thursday $6^{\text {th }}$ June}

\subsection{5am}

Following a suggestion from Anne yesterday, I have started conducting a survey of readers in the historic collections reading room twice a day to find out if they use the SHL catalogue and how they found out that the material they wanted was in SHL. After my first attempt at this yesterday afternoon, I am going to add a follow up question about whether they do a search for a large number of items and then save the list of results or whether they search 
for one item at a time. The aim of this survey is to get some indication of why I have had trouble recruiting special collections readers.

Thoughts from listening to recorded interview for Participant G:

- Thinking that subject searching does not find everything relevant - search again using other words

- Googling books to find out what they are about because not enough information in the catalogue

\subsection{0pm}

Thoughts from listening to recorded interview for Participant $\mathrm{H}$ :

- Use of Google to find book title - known item with known author and subject, but no title

- Using catalogue to find out what has been written on a subject - don't even know if the field exists, haven't searched anywhere else before - so came to catalogue before Google

- Looking for books to direct students to

- Difficulty finding databases through catalogue

- Occasional use of advanced search - but don't tend to need it, main search usually works

- Never noticed facets or refine by down the left-hand sidebar - when looks at, not obvious what it does, but when I explain what it does, says this would be useful

- Problem of search bringing up items in other libraries she cannot access

- Goes into full record for date of publication because catalogue at home institution doesn't show this in results list

Thoughts from listening to recorded interview for Participant I: 
- Usually use catalogue before coming to library and write list of everything going to need for a day

- When goes to shelf finds things which, from catalogue, didn't think would be useful and useful things that didn't find on catalogue

- Don't use catalogue for subject searching

- Hadn't noticed left-hand sidebar, but says they would be useful

- Subjects not useful - all the same for material she uses

\section{$6.30 \mathrm{pm}$}

Participant J was interesting because she struggled with the catalogue and went to ask the service desk staff for help. Unfortunately, I realised when writing up I hadn't been able to make enough notes to capture her conversation with the member of staff accurately they're were obviously bits missing. I could use just the observation notes from the search, with a summary of her exchange with the member of staff and a write of the interview notes or I could exclude this participant from the analysis. I have not decided yet which is the better course of action.

Have finished writing up notes from today's participants and decided not to do any more observations today. I'm tired and think I would struggle to make good observation notes. I already have 10 participants and should be able to get at least 2 tomorrow, so I will have plenty of data to analyse.

\section{Friday $7^{\text {th }}$ June}

\section{$10 a m$}

Thoughts from listening to recorded interview for Participant J:

- Only knew author for book - assumed if used author in quick search the catalogue would expect that in the title, 
- Was looking for somewhere to search for journals in whole of University of London Colleges - was expecting access to all colleges e-journals in SHL

- Wanted to find a help function

Having re-read the notes I have made so far, some emerging themes are:

- Use of Copac to find items first (and then do known item search on SHL catalogue) people who aren't keen on SHL catalogue

- Expectation that some level of skill needed to use the catalogue - idea that they are not doing it the right way, or don't know what they're doing

- Saved searches only kept for session is a problem

- Availability of item and it being in a library that person can access / isn't far away often important, but not everyone for whom this was the case noticed the option to refine by location / understood what it did

- Catalogue use for browsing 